\title{
The cellular biology of atherosclerosis with atherosclerotic lesion classification and biomarkers
}

\author{
Leta Melaku ${ }^{1 *}$ and Addisu Dabi ${ }^{2}$
}

\begin{abstract}
Background: Atherosclerosis is a chronic lipid-driven inflammatory disease with infiltration of low-density lipoprotein and is considered as the pivotal step in plaque formation. The aim of the review is to get into the fine details of pathophysiologic mechanisms responsible for atherosclerosis with atherosclerotic lesion classification. It also provides a summary of current biomarkers other than the traditional risk factors so that new treatment modalities can emerge and reduce the morbidity and mortality associated with atherosclerosis.

Main body: In the classification of atherosclerosis made by American Heart Association (AHA), AHA Type I lesion is the earliest vascular change described microscopically. AHA Type II lesion is primarily composed of abundant macrophages. AHA Type III lesion is the earliest of progressive lesions, while AHA Type IV lesion consists of an acellular necrotic core. Various biomarkers are implicated in different stages of the pathophysiological mechanism of plaque formation and evolution. C Reactive Protein plays a direct role in promoting the inflammatory component of atherosclerosis. Fibrinogen was demonstrated to be elevated among patients with acute thrombosis. Higher leukocyte count is associated with a greater cardiovascular risk. Cytokines have been implicated in atheroma formation and complications. High rates of protease activated receptor expression are also induced by interleukin- 6 secretion in atherosclerotic lesions and areas of vascular tissue injury. Cluster of differentiation 40 receptor and its ligand have been also detected in atherosclerotic plaques. Osteopontin, acidic phosphoprotein, and osteoprotegerin have emerged as novel markers of atherosclerotic plaque composition. There are also overproductions of matrix metalloproteinases in the rupture-prone regions and promote lipid-necrotic core formation in the atherosclerotic plaque. Myeloperoxidase has been proposed as a marker of plaque instability. Oxidized low-density lipoprotein receptor 1 provides a route of entry for oxidized low-density lipoprotein into the endothelium. A human atherosclerotic lesion also expresses lipoprotein-associated phospholipase $\mathrm{A}_{2}$.
\end{abstract}

Short conclusion: Atherosclerotic plaques are the battlefield between an unbalanced immune response and lipid accumulation in the intima of arteries. Most of the biomarkers associated with atherosclerosis are indicators of inflammatory response and will also be used for medical purposes.

Keywords: Atherosclerosis, Low-density lipoprotein, Atherosclerotic plaques, Inflammation, Lesion classification, Clinical biomarker and risk prediction

\footnotetext{
${ }^{*}$ Correspondence: letamelaku@gmail.com

${ }^{1}$ Department of Biomedical Sciences, College of Health Sciences, Arsi

University, Asella, Oromia, Ethiopia

Full list of author information is available at the end of the article
}

\section{Background}

Atherosclerosis is a chronic lipid-driven inflammatory disease characterized by a complex endocrine, paracrine and juxtacrine cross-talk between immune and vascular cells as well as several tissues and organs, including the liver, heart, kidney, adipose tissue, adrenal, pancreatic, 
pituitary and sex glands (Badimon et al. 2012; Libby 2012). The first step in the development of atherosclerosis is the exposure of vascular cells to excess lipid with concomitant endothelial activation/dysfunction and the internalization and deposition of lipids in the intima (Badimon and Vilahur 2014). Sites with low or oscillatory endothelial shear stress, located near branch points and along inner curvatures, are the most susceptible (Wentzel et al. 2012). Before development of atherosclerosis, these predilection sites are characterized by changes in endothelial turnover and gene expression (Wentzel et al. 2012), the presence of subendothelial dendritic cells (Millonig et al. 2001) and, in humans, by the presence of adaptive intimal thickening (Schwartz et al. 1995) and with time, the disease spreads to adjacent intima (Velican and Velican 1980). Although the "first event" favoring early lipid deposition within the arterial sub-intimal space has not been identified, the infiltration of low-density lipoproteins (LDL) should be considered as the pivotal step in plaque formation (Hansson 2005). Atherosclerotic plaques are the battlefield among an unbalanced immune response and lipid accumulation in the intima of arteries (Montecucco 2009). Several factors such as smoking, hyperlipidemic states, diabetes, hypertension, physical activity and arterial hypertension are seen to contribute to the genesis of atherosclerosis (Fig. 1) (Novo et al. 1991, 1992) however, any one of these alone is insufficient to produce an atherosclerotic lesion (Singh et al. 2002). With the development of plaque and remodeling of arterial wall, local flow patterns change. This dynamic interplay between flow and the vessel wall may influence the progression of the disease and ultimately the fate of the lesions (Bentzon et al. 2014). The growth of the lesion is abluminal in early stages of the disease, and the progress may vary from total cessation in some cases to very rapid with intervening periods of relative quiescence (Libby et al. 1998). Distinct clinical manifestations are seen depending on the type of vascular bed affected by atherosclerosis because it reduces the perfusion of a tissue.

Powerful laboratory research in the past decade has led to many reviews that describe the biological and genetic bases of atherosclerosis (Lusis 2000; Glass and Witztum 2001; Libby 2003). Despite this progress, the leap from experimental-animal findings to human atherosclerosis and clinical application presents challenges. The laboratory literature and experimental community sometimes assume that the results obtained in cultured cells or animals closely correspond to humans. Although experimental work has helped to unravel some of the principles of atherosclerosis pathophysiology, gaps remain in translation to the clinic, and these breeches require bridging to achieve the full promise of scientific advances in atherosclerosis. This review summarizes the pathophysiology of atherosclerosis plaque progression with emphasis on

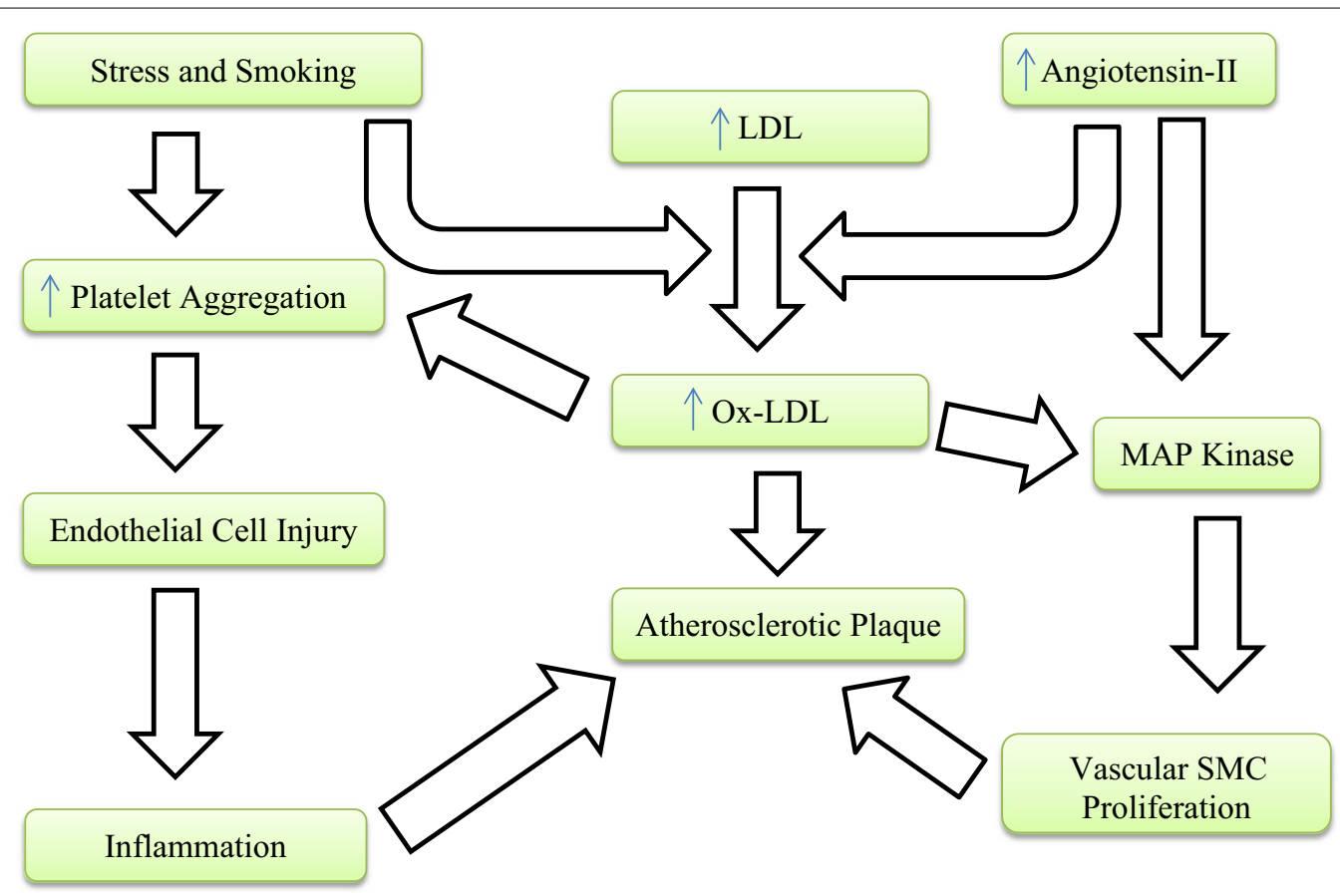

Fig. 1 Schematic design depicting the involvement of oxidized low density lipoprotein (oxLDL), injury of endothelial cells and proliferation of vascular smooth muscle cells (SMC) in the development of atherosclerotic plaque. MAP Mitogen-activated protein 
plaque progression. It also offers the recently published literature on different biomarkers and examine whether incorporation of these markers might improve clinical decision.

Atherosclerosis begins with fatty streak which is an accumulation of lipid laden foam cells in the intimal layer of the artery (Alexander and Dzau 2000). Lipid retention is the first step in the pathogenesis of atherosclerosis which is followed by chronic inflammation at susceptible sites in the walls of the major arteries lead to fatty streaks, which then progress to fibroatheromas which are fibrous in nature (Collins et al. 2003; Pedrigi et al. 2014). The location of atherosclerotic lesions varies between men and women. Among women, atherosclerotic lesions are located in the carotid arteries-24.1\%; coronary arteries-4.5\%; abdominal aorta-22.8\% and ilio-lumbar arteries-30.1\%. Among men, the incidence of atherosclerosis in the above locations is as follows: $36.9 \%$; 26.1\%; 27.2\% and 54.1\% (Fernández-Friera et al. 2015).

The first classification of atherosclerosis was made by the WHO in 1958 and comprised the following sequence: fatty streak, atheroma, fibrous plaque, and complicated lesions (WHO Study Group on the Classification of Atherosclerotic Lesions and World Health Organization 1958). In the mid-1990s, the American Heart Association (AHA) recommended a new morphological classification based on six lesion types which denote atherosclerosis lesion progression (Stary et al. 1995). Virmani et al. (2000) and van der Wal et al. (1994) further redefined this classification based on the premise that plaque erosion triggers coronary thrombosis.

\section{Histological classification of atherosclerotic lesions}

Histological classification for atherosclerotic lesions employs a numerical grade based on the characteristics of the plaque (Stary et al. 1995).

\section{Intimal thickening and fatty streaks}

The term "initial lesion" has also been used for type I. Type I lesions have been described as being most frequent in infants and children. However, such initial lesions can also be found in adults, particularly in those with little atherosclerosis, or in locations of arteries that are lesion resistant (Stary et al. 1994). The initial histological changes in the human intima are minimal. The earliest vascular change described microscopically is intimal thickening (AHA Type I lesion), which consists of layers of smooth muscle cells and extracellular matrix with small, isolated groups of macrophages containing lipid droplets (macrophage foam cells) form (Stary 1987, 1989). Smooth muscle cell proliferation was observed in the media before birth but was rare after birth, whereas the intima replication index was $2-5 \%$
(Ikari et al. 1999). Although intimal thickening is more frequent in atherosclerosis-prone arteries such as coronary, carotid, abdominal and descending aorta, and iliac arteries (Nakashima et al. 2002), the change is considered adaptive (non-atherosclerotic) since the SMCs exhibit a very low proliferative activity later in life and show antiapoptotic phenotype (Imanishi et al. 2000; Orekhov et al. 1998).

Type II lesions include fatty streaks, which on gross inspection may be visible as yellow-colored streaks, patches, or spots on the intimal surface of arteries (Stary et al. 1994). The termed "intimal xanthoma" or "fatty streak" (AHA Type II lesion), is a lesion primarily composed of abundant macrophage foam cells interspersed within a smooth muscle cells (SMCs) and proteoglycan rich intima (Fig. 2) (Sakakura et al. 2013).

Microscopically, type II lesions are more distinctly defined than type I lesions. They consist primarily of macrophage foam cells stratified in adjacent layers rather than being present as only isolated groups of a few cells. Intimal smooth muscle cells, in addition to macrophages, now also contain lipid droplets. Type II lesions contain greater numbers of macrophages without lipid droplets than do type I lesions or the normal intima (Stary et al. 1994). T lymphocytes have been identified in type II (Katsuda et al. 1992; Munro et al. 1987), but they are less numerous than macrophages. Although this entity is considered by AHA classification as the earliest lesion of atherosclerosis, this lesion is a reversible process (with little progressive tendencies). Elegant studies of video microscopy have shown that foamy macrophages may leave the wall by passage between endothelial cells into the lumen (Ley et al. 2007). It is clear that lesions in the thoracic aorta, abdominal ventral aorta and mid right coronary lesions may regress with advancing age (1534 years) (Natural history of aortic and coronary atherosclerotic lesions in youth 1993).

\section{Pathologic intimal thickening}

The earliest of progressive lesions is the pathologic intimal thickening (PIT, AHA Type III lesion), which is primarily composed of layers of smooth muscle cells in a proteoglycan-collagen matrix that is aggregated near the lumen with an underlying lipid pool consisting of an acellular area, rich in hyaluronan and proteoglycans (mainly versican) with lipid insudation (Virmani et al. 2000). The designation "type III lesion" applies solely to lesions that form the morphological and chemical bridge between type II lesions and atheromas (Stary et al. 1994). The type III lesion is also known as the intermediate lesion, the transitional lesion, and as preatheroma. Its characteristic histological features are microscopically visible extracellular lipid droplets and particles to the extent that pools 


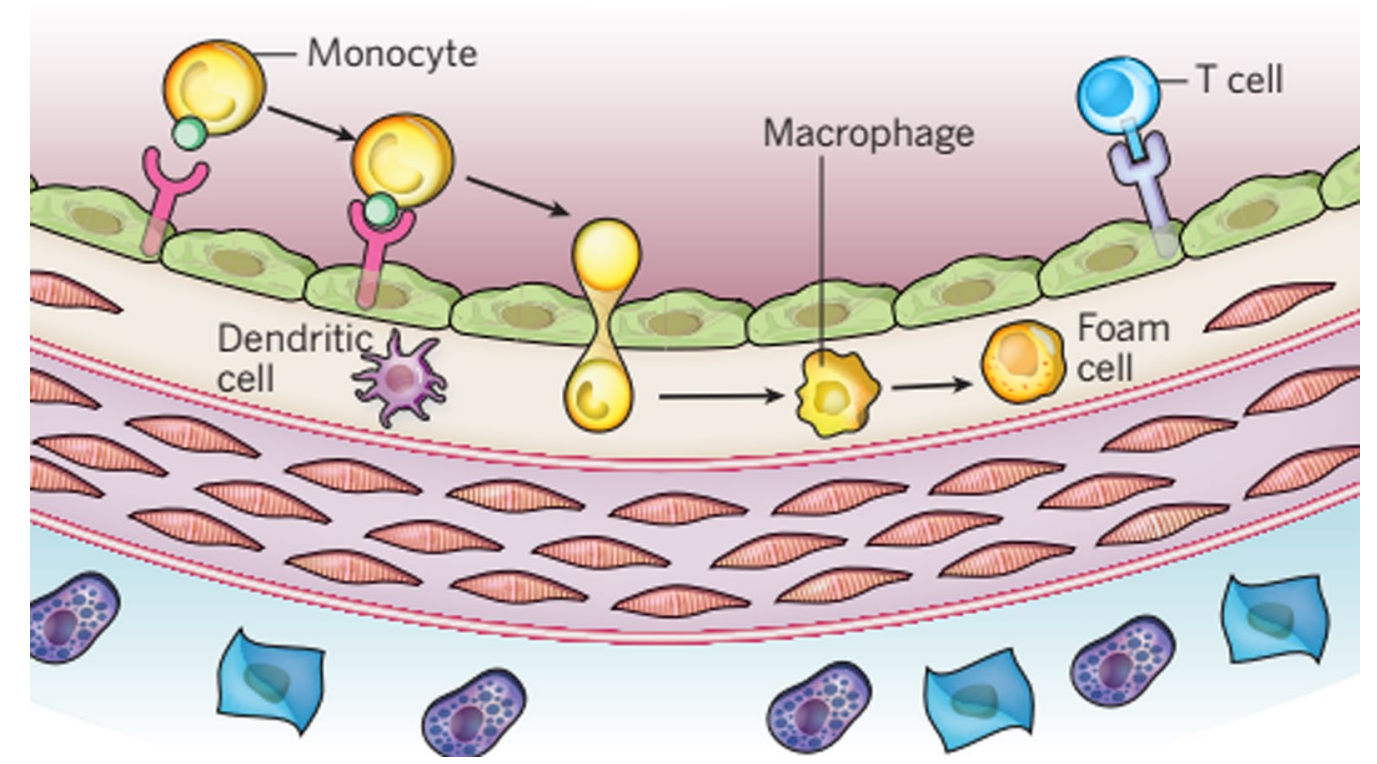

Fig. 2 The initial steps of atherosclerosis. It include adhesion of blood leukocytes to the activated endothelial monolayer, directed migration of the bound leukocytes into the intima, maturation of monocytes (the most numerous of the leukocytes recruited) into macrophages, and their uptake of lipid, yielding foam cells

of this material form among the layers of smooth muscle cells of the generally collocalized adaptive intimal thickening (Stary et al. 1994). Another important hallmark of PIT is the variable accumulation of macrophages on the luminal aspect of the plaque (outside the lipid pool) (Fig. 3), although they are not observed in all lesions of PIT (Sakakura et al. 2013). Apoptotic SMCs within lipid pools are recognized by the presence of a thick basement membrane that surrounds the area previously occupied by the smooth muscle cell (cages of the basal lamina) (Sakakura et al. 2013). Type III lesions are found in young adults (Stary et al. 1994).

\section{Atheroma, fibroatheroma and complicated lesions}

Atheroma, classified as AHA Type IV lesion, is the first lesion type considered as advanced lesions by histological criteria because there is a lipid core that is wellformed with foam cells and extracellular deposits in the form of cholesterol crystals (Stary et al. 1994). Type V lesions, or fibroatheroma, are characterized by a welldeveloped lipid core covered by a fibrous capsule (Dos Santos et al. 2021). Fibroatheromas consist of an acellular necrotic core, which is distinguished from lipid pool areas of PIT, as it is made up of cellular debris and is devoid of matrix which is best appreciated by sirius red staining (Fig. 4) (Sakakura et al. 2013). The necrotic core is also covered by a thick fibrous cap consisting of smooth muscle cells in a proteoglycan-collagen matrix (Virmani et al. 2000). For the better understanding of how necrotic cores evolve, fibroatheromas are subclassified into those with "early" and "late" necrotic cores. Lesions of early necrotic core characteristically exhibit proteoglycans, versican, and biglycan and hyaluronan, which are typically absent in late necrotic cores (Sakakura et al. 2013).

Early necrotic core is identified by the presence of foamy macrophage seen infiltration into the luminal surface of the lipid pools. It coincides with the focal presence of calcifying macrophages and the presence of large free cholesterol clefts; there is definite lysis of the extracellular matrix. The late necrotic cores no longer stain for hyaluronan or proteoglycans and on Sirius red stains there is absence of any collagenous matrix. Notably, the majority of macrophages within the areas of necrotic core display features consistent with apoptotic cell death although autophagic processes may also play a role (Bao et al. 2006). The presence of free cholesterol is another discriminating feature of the late necrotic core and is partially attributed to apoptotic cell death of macrophages, in part regulated by acetyl-CoA acetyltransferase 1 (ACAT1) (Tabas 2000). The death of macrophages in the setting of defective phagocytic clearance of apoptotic cells is thought to contribute further to the development of plaque necrosis (Tabas 2000; Tabas et al. 1996). The necrotic core area is surrounded by an overlying layer of thick "fibrous cap" composed mostly of type I and III collagen, proteoglycans and interspersed smooth muscle cells (Sakakura et al. 2013). The fibrous cap is critical for 


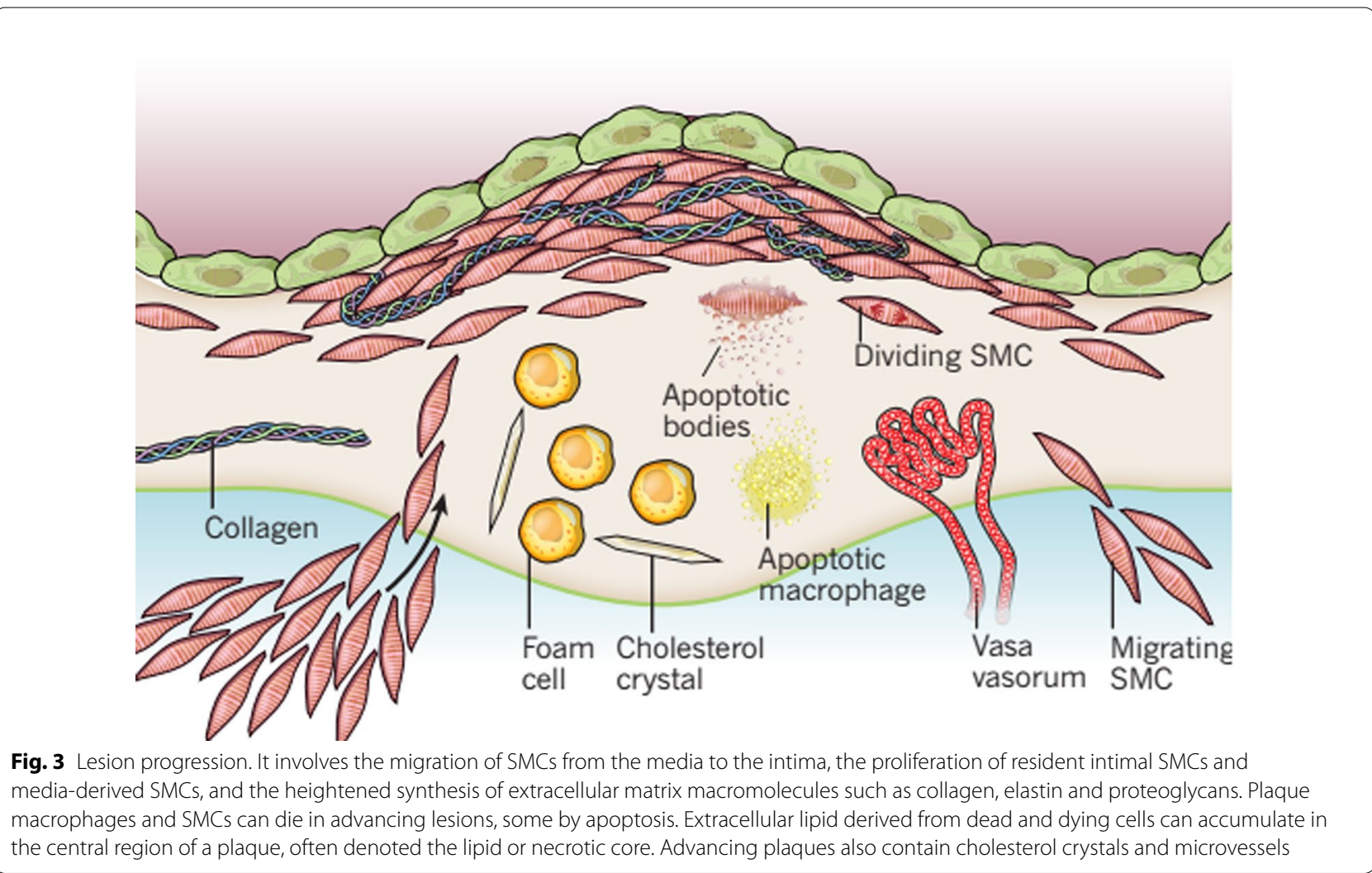

the maintenance of the integrity of the lesion and is subject to thinning, prior to rupture.

Type VI lesions are known as complicated lesions, because of presence of disorders such as intraplaque hemorrhage, fissures, erosions, or thrombosis (Stary et al. 1995). An update to this classification provided greater detail on complicated lesions, adding type VII atherosclerotic lesions, in which calcification predominates, and type VIII lesions, in which fibrosis predominates (Stary 2000). The progression of lesions does not necessarily occur in a single direction or in a strictly sequential manner (Stary 2000). Atheromas, or advanced type IV lesions, can develop directly to types V, VI, VII, or VIII, without necessarily proceeding through each of those stages (Stary 2000).

\section{Morphological classification of atherosclerotic lesions}

Other classifications have been proposed in the literature, also based on atherosclerotic lesions in coronary arteries, but considering presence of erosion and plaque rupture and also presence of thrombi (Virmani et al. 2000). The morphology of atherosclerotic plaques plays an important role in clinical presentation. Whereas clinically evident chronic obstructive lesions are generally fibroatheromas, in which the lipid core is small and the fibrous cap is well developed, making the artery more rigid, acute obstructions due to thrombosis more frequently form on plaques with a large lipid core and a thin or inexistent fibrous cap, known as thin-cap fibroatheromas, soft plaques, or vulnerable plaques (Finn et al. 2010). The well-developed lipid core is indicative of predominance of the proinflammatory environment, with large numbers of activated macrophages secreting metalloproteinases that lyse the fibrous cap and make the plaque more predisposed to fissures and ulcerations (Libby et al. 2009). Clinical presentation can vary depending on the degree of lumen obstruction and the velocity with which the obstruction develops (Dos Santos et al. 2021). Chronic obstruction can become clinically evident when the lumen is reduced by at least $70 \%$. However, acute obstructions, associated with thrombosis, can occur with clinically silent plaques (Dos Santos et al. 2021). In the peripheral arteries, a study of patients with peripheral arterial occlusive disease (PAOD) showed that in patients who had undergone an amputation there were advanced atherosclerotic lesions in arterial segments, the majority of which were types V and VI, with degree of obstruction exceeding 75\% (Santos et al. 2008). Another study including cases with critical limb ischemia, and analyzing arteries of amputated lower limbs, found a predominance of fibroatheroma lesions and plaques with fibrocalcification 


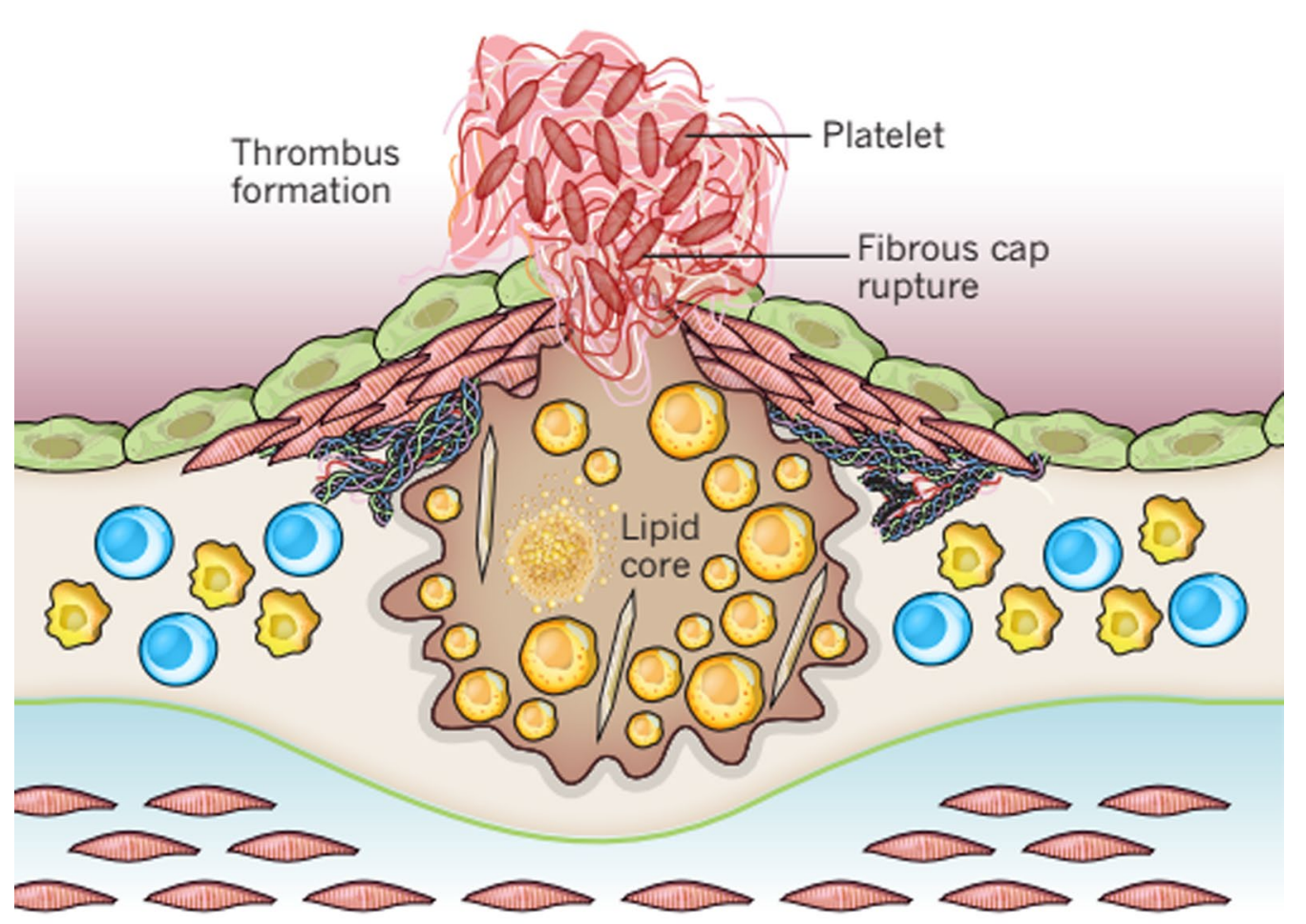

Fig. 4 Thrombosis. It is the ultimate complication of atherosclerosis, often complicates a physical disruption of the atherosclerotic plaque. A fracture of the plaque's fibrous cap, which has enabled blood coagulation components to come into contact with tissue factors in the plaque's interior, triggering the thrombus that extends into the vessel lumen, where it can impede blood flow

in the femoropopliteal segment, and an elevated frequency of thrombi and calcification of the tunica media in infrapopliteal arteries (Narula et al. 2018).

A comprehensive morphological classification scheme for atherosclerotic lesions is bases on the 7 categories: intimal xanthoma, intimal thickening, pathological intimal thickening, fibrous cap atheroma, thin fibrous cap atheroma, calcified nodule, and fibrocalcific plaque (Virmani et al. 2000). The key features defining these categories are the accretion of lipid in relationship to formation of the fibrous cap, changes over time in the lipid to form a necrotic core, thickening or thinning of the fibrous cap, and thrombosis (Virmani et al. 2000).

\section{Intimal xanthomata}

"Xanthoma" is a general pathological term that describes focal accumulations of fat-laden macrophages. In humans, most of these intimal xanthomata regress, since the distribution of lesions in the third decade of life and beyond is very different from the fatty streaks seen in children (Velican and Velican 1980). The presence of an intimal xanthoma is not a basis for categorizing lesions in current animal models as "atherosclerotic" (Virmani et al. 2000). This is problematic, based on the fact that the distribution of lesions in animal models is very different from that in the adult human population (Wissler and Vesselinovitch 1968) and the potential for these lesions to regress (Armstrong et al. 1990; Strong et al. 1999).

\section{Intimal thickening}

While some human lesions may begin as intimal xanthomata, most adult human lesions originate as preexisting intimal masses (Virmani et al. 2000). Evidence for this tenet comes in part from studies by Kim et al. (1987). who showed that atherosclerotic lesions produced in the coronary arteries of hypercholesterolemic swine arise almost exclusively from intimal cell masses. Moreover, the distribution of these normal, developmental intimal masses in children can be correlated with the distribution of characteristic lesions seen in adult humans (Schwartz et al. 1995; Velican and Velican 1980). The origin of fat accumulation subjacent to initially small, very focal, preexisting intimal masses may explain the following paradox. There is very little evidence of cell replication except in early lesions, yet the smooth muscle cells of adult lesion are usually clonal (McCaffrey et al. 1997; Schwartz et al. 1995). Very few replications over a long time could easily account for quite sizeable atherosclerotic lesions. 
Thus, the clonality of the lesions may provide a teleological clue, suggesting that the properties of these normal intimal structures may be relevant to the earliest events in the formation of human lesions. Tabas et al., for example, have proposed that the extracellular matrix at these sites may contain enzymes capable of retaining lipids, an initial event in the formation of the necrotic core (Tabas et al. 1993). Unfortunately, there are very few articles on the evolution of early intimal cell masses in humans, and none of these clarify their precise pathological mechanisms of development. Another reason for considering the role of the intima in giving rise to clinically significant lesions comes from the observation that the majority of erosions occur over areas of intimal thickening, with minimal or no evidence of a lipid core (Virmani et al. 2000).

\section{Fibrous cap atheromata}

The AHA classification distinguishes between lesion types IV and V on the basis of the degree of fibrous cap formation, the extent to which the lipid core becomes rich in cellular debris, and the development of complicating features (Stary et al. 1995). Because there is no clear evidence of a specific sequence of events that relate the extent of changes in the lipid core to the development of a fibrous cap, the use of descriptive terms for plaque classification was suggested. Virmani and his colleaguesdefineda "fibrous cap" as a distinct layer of connective tissue completely covering the lipid core (Virmani et al. 2000). The fibrous cap consists purely of smooth muscle cells in a collagenous proteoglycan matrix, with varying degrees of infiltration by macrophages and lymphocytes. Thus, a fibrous cap atheroma may have a thick or thin cap overlying a lipid-rich core. The lipid core is also part of our classification. As lesions progress, the core of necrotic debris surrounded by macrophages becomes increasingly consolidated into 1 or more masses comprising large amounts of extracellular lipid, cholesterol crystals, and necrotic debris (Virmani et al. 2000).

\section{Thin fibrous cap atheromata}

Thin fibrous cap atheroma is a specific plaque type not recognized by the current AHA classification (Stary et al. 1995). Lesions with thin, fibrous caps are those that are most likely to rupture (Burke et al. 1997). The AHA's discussion suggests this as well; however, their classification scheme also describes type IV lesions as showing fissuring and hemorrhage, including rupture, of the fibrous cap (Stary et al. 1995). Virmani and his colleaguesdefined a "thin," fibrous cap as 1 that is $<65 \mu \mathrm{m}$ thick (Virmani et al. 2000). This definition was derived from a morphometric series of 41 ruptured plaques, in which $95 \%$ of the caps measured, $<65 \mu \mathrm{m}$ thick; the mean \pm SD plaque thickness was $23 \pm 19 \mu \mathrm{m}$ (Burke et al. 1997). The thin, fibrous cap is distinguished from the earlier fibrous cap lesions by the loss of smooth muscle cells, extracellular matrix, and inflammatory infiltrate. The necrotic core underlying the thin, fibrous cap is usually large; hemorrhage and/or calcification is often present; and intraplaque vasa vasorum are abundant (de Feyter et al. 1995; Fishbein and Siegel 1996).

\section{Lesions with thrombi}

Rather than creating separate lesion types for rupture and thrombosis, the simplified scheme proposed to classify lesions with thrombi as being affected principally by 3 distinct processes: rupture, erosion, and, less frequently, the calcified nodule. These processes can occur in the setting of a fibrous cap atheroma or, in the case of erosion, pathological intimal thickening (Virmani et al. 2000). A single lesion may contain morphological evidence of both rupture and erosion.

"Plaque rupture" is defined by an area of fibrous cap disruption whereby the overlying thrombus is in continuity with the underlying necrotic core (Virmani et al. 2000). Ruptured lesions typically have a large necrotic core and a disrupted fibrous cap infiltrated by macrophages and lymphocytes. The smooth muscle cell content within the fibrous cap at the rupture site may be quite sparse (Virmani et al. 2000). Risk factors most predictive for this type of lesion are hypercholesterolemia, low serum HDL, and high total cholesterol to HDL cholesterol ratio (Burke et al. 1997). In women $>50$ years old, ruptured plaques compose the vast majority of atherosclerotic lesions associated with acute thrombi, and similar to men, there is an association with increased total cholesterol levels (Burke et al. 1998).

"Plaque erosion" is identified when serial sectioning of a thrombosed arterial segment fails to reveal fibrous cap rupture. Typically, the endothelium is absent at the erosion site. The exposed intima consists predominantly of smooth muscle and proteoglycans, and surprisingly, the eroded site contains minimal inflammation (Farb et al. 1996; van der Wal et al. 1994). The term "erosion" was chosen to used, despite its mechanistic implication, because unaware of evidence that such large areas of endothelium are ever absent in nonthrombosed vessels, even over advanced lesions (Davies et al. 1988; Kolodgie et al. 1990; Rosenfeld et al. 1987; Taylor et al. 1989). Erosions constitute approximately $40 \%$ of cases of thrombotic sudden coronary death (Farb et al. 1996). Plaque erosions are more common in young women and men $<50$ years of age and are associated with smoking, especially in premenopausal women (Virmani et al. 2000). 


\section{Calcified nodule}

A second lesion, albeit an infrequent cause of thrombotic occlusion without rupture, is referred to as a "calcified nodule." This term refers to a lesion with fibrous cap disruption and thrombi associated with eruptive, dense, calcific nodules. The origin of this lesion is not precisely known, but it appears to be associated with healed plaques. Interestingly, these lesions are found predominantly in the midright coronary artery, where coronary torsion stress is maximal (Virmani et al. 2000). It is unclear whether the fibrous cap wears down from physical forces exerted by the nodules themselves, proteases from the surrounding cellular infiltrate, or both. Thin fibrous cap lesions with eruptive, calcified nodules should not to be confused with fibrocalcific lesions that are not associated with thrombi (Virmani et al. 2000). The latter appear to be the end result of fibrosis and calcification and are often associated with a narrowed lumen. Moreover, this entity does not appear to be a variant of rupture with calcification, since the nodules themselves appear in the lumen in the absence of an overt intimal tear (Virmani et al. 2000).

\section{Fibrocalcific lesions}

Some plaques have thick, fibrous caps overlying extensive accumulations of calcium in the intima close to the media (Kragel et al. 1989). Because the lipid-laden necrotic core, if present, is usually small, we refer to this category of lesion as fibrocalcific rather than atheroma. The fibrocalcific lesion is the end stage of a process of atheromatous plaque rupture and/or erosion with healing and calcification (Virmani et al. 2000).

\section{Biomarkers of atherosclerotic plaques formation}

Biomarkers are molecules that serve as indicators of biologic and pathogenic processes in living systems (Boamponsem and Boamponsem 2011). Most of the biomarkers associated with atherosclerosis are indicators of inflammatory response. Various biomarkers have been studied as candidates for monitoring the progression of atherosclerotic disease and the majority of them are implicated in different stages of the pathophysiological mechanism of plaque formation and evolution (Fig. 5). As a consequence, the diagnostic/prognostic weight of each one of them leans either towards progression or to the direction of plaque destabilization (Defraigne 2007). In order to detect a vulnerable atherosclerotic plaque that is more likely to cause cardiovascular events, one should focus on studying biomarkers more associated with destabilization rather than disease progression (Triantafllos et al. 2011). Therefore, detection of vulnerable or rupture-prone lesions is of paramount importance so that necessary clinical steps can be taken to prevent the deleterious clinical sequel associated with symptomatic plaque rupture. Specificity and sensitivity vary for each one of these biological markers and they are also different for each vascular bed.

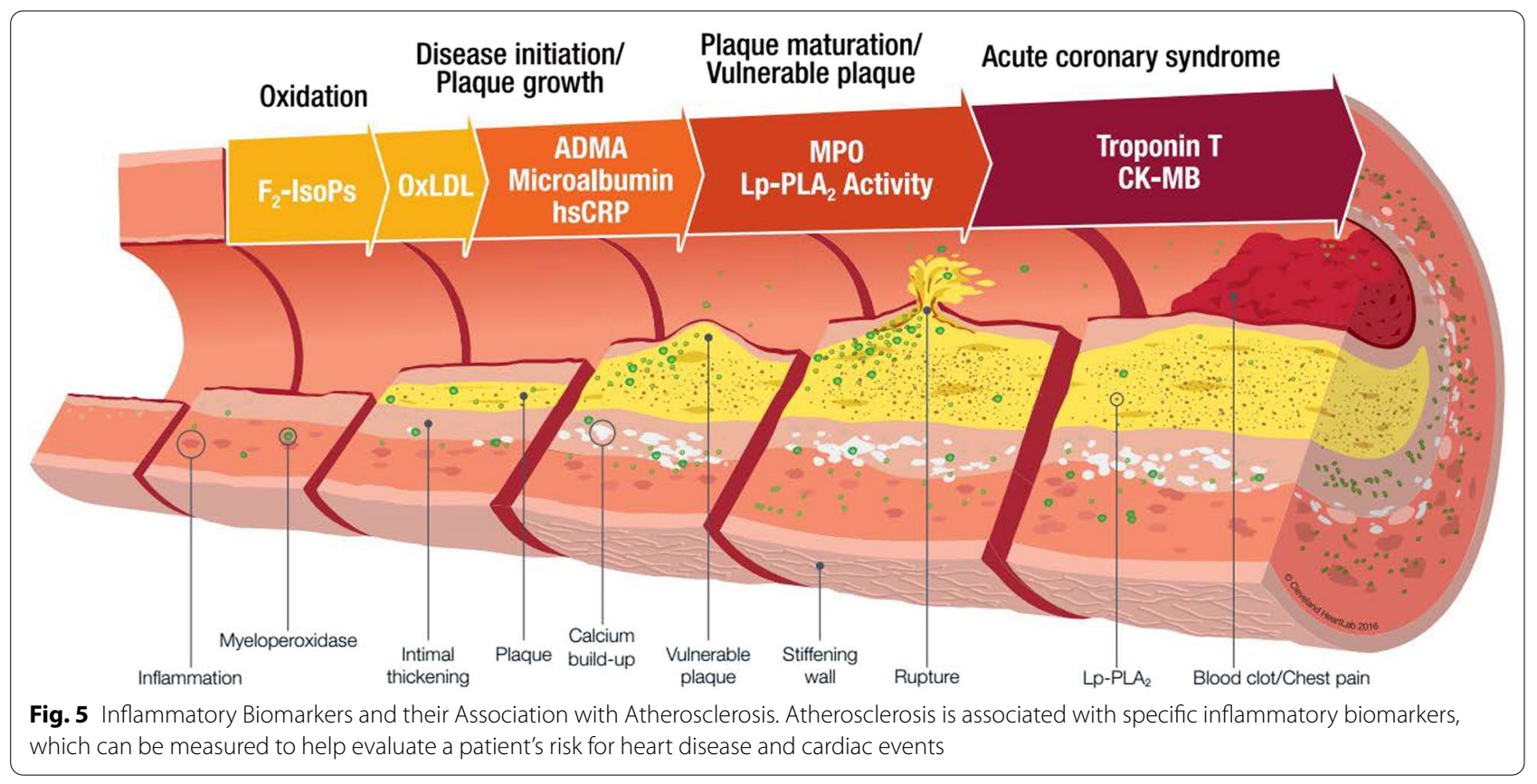




\section{Complement reactive protein and pentraxin-3}

Complement reactive protein (CRP) is an acute phase protein, primarily synthesized by hepatocytes, and induced by IL- 6 with synergistic enhancement of IL-1 or TNF (Volanakis 2001). It was discovered that there was an up regulation of CRP and complement protein levels in plaque tissues (Yasojima et al. 2001). CRP has been proposed to induce a prothrombotic state via induction of tissue factor expression in human monocytes (Paffen et al. 2004). It has been also demonstrated to decrease the expression and bioactivity of endothelial nitric oxide synthase with a subsequent effect on vasodilatation (Venugopal et al. 2002). Subsequently, CRP enhances the release of endothelin (ET-1), adhesion molecules (VCAM-1, ICAM), chemoattractants (MCP-1), migration of SMCs as well as facilitate LDL uptake by macrophage (Verma et al. 2002; Yasojima et al. 2001). Endothelium responds to CRP by intensifying the release of NFkB which initiates the release of cytokines and mediates cell apoptosis (Yasojima et al. 2001). CRP down-regulates both basal and VEGF stimulated angiogenesis, whereas it promotes endothelial apoptosis in a nitrous oxide-dependent fashion (Verma et al. 2004). CRP has been also found to synergistically enhance angiotensin II-induced proinflammatory effects, involving cellular migration and proliferation as well as lesion collagen and elastin content (Wang et al. 2003). These findings support the hypothesis that CRP may play a direct role in promoting the inflammatory component of atherosclerosis and present a potential target for the treatment of atherosclerosis. Unlike many other inflammatory mediators, CRP is not subject to diurnal fluctuation or biological variance, and CRP concentration appears to be proportional to disease severity (Zaninotto et al. 2007). Unfortunately, CRP major limitation is its elevation in systemic inflammation (Zaninotto et al. 2007), which may limit its use as a prognostic marker in postoperative patients.

High sensitivity (hs)-CRP measures accurately levels of CRP to identify low but persistent levels of inflammation. Therefore, high sensitivity (hs)-CRP is vital in predicting atherosclerosis and as such serve as valuable tools in the diagnosis and prognosis of atherosclerosis. According to the European Society of Cardiology guidelines for cardiovascular disease prevention in clinical practice, hs-CRP levels may be measured as part of refined risk assessment only in patients with an unusual or moderate risk profile (class IIb/B recommendation), but not in asymptomatic lowrisk or high-risk individuals (class III/B recommendation) (Piepoli et al. 2016), whereas the American College of Cardiology/American Heart Association guidelines state that hs-CRP measurement may be considered if, after quantitative risk assessment, a risk-based treatment decision is uncertain (class IIb/B recommendation) (Goff et al. 2014). A recent large series including more than 1600 patients with asymptomatic carotid atherosclerosis prospectively followed for a median of 11.81 years, found that the risk of all-cause and cardiovascular mortality significantly increased in patients with elevated serum levels of hs-CRP. That risk was level response associated and patients with carotid narrowing of greater than $50 \%$ and hs-CRP levels of greater than $0.29 \mathrm{mg} / \mathrm{dL}$ had nearly twice as high a risk of cardiovascular mortality compared with patients with carotid stenosis of less than $50 \%$ and hs-CRP levels of less than $0.29 \mathrm{mg} / \mathrm{dL}$ (Mayer et al. 2016). This association with carotid disease, however, is also controversial. Some studies suggest that high serum hs-CRP levels can predict the presence of carotid plaque (Debing et al. 2008; Schulze Horn et al. 2009; Puz et al. 2013), although other studies could not establish that association (Chapman et al. 2004; Halvorsen et al. 2009) or any correlation with the degree of stenosis (Puz et al. 2013; Eltoft et al. 2017). Plaque type relation to hs-CRP levels is also diverse: some studies report association with echolucent plaques (Rozalski et al. 2013; Yamagami et al. 2004), but other studies correlated hs-CRP levels with increased plaque volume, but not with echolucency (Grønholdt et al. 2001; Halvorsen et al. 2009) or grey-scale median (GSM) value (Andersson et al. 2009a). hs-CRP may predict plaque instability on MR imaging (hypointensity in T1 weighted images)(Shindo et al. 2014) and levels $5 \mathrm{mg} / \mathrm{L}$ or greater were significantly associated with a greater number of new cerebral lesions detected on diffusion weighted MR imaging during carotid artery stenting (Pini et al. 2013), but did not correlate with plaque inflammation as determined by carotid artery fluorodeoxyglucose (FDG) uptake on positron emission tomography (PET)(Duivenvoorden et al. 2013; Rudd et al. 2009). A recently reported large series found no significant association between progression of carotid intima-media thickness (cIMT) over a 2-year period and average hsCRP levels; values were also not related in a doseresponse manner, assuming it might be considered as risk marker rather than a causal factor (Wang et al. 2017). Nevertheless, elevated baseline hs-CRP levels were independently associated with increased ischemic stroke risk in a meta-analysis summarizing results of 12 studies, which included more than 2000 patients (Zhou et al. 2016) and also predicted early restenosis after carotid endarterectomy (Tanaskovic et al. 2018).

Pentraxin-3 (PTX3) is another acute phase protein that has been reported associated with the presence of atherosclerotic plaques (Knoflach et al. 2012) and elevated levels of PTX3 were also found in patients with plaque instability undergoing carotid stenting (Shindo et al. 2014). Nevertheless, the association with the presence and severity of carotid stenosis is questioned in other 
studies (Bonacina et al. 2013; Norata et al. 2008) and a population-based study involving more than 2400 subjects, showed that PTX3 is not a predictor of incident cardiovascular events (Baragetti et al. 2014).

\section{i. Haematological and neovascularization bio- markers}

An alteration of the different subsets of blood cells may reflect a state of activation or prolonged inflammation in a nonspecific fashion. Red blood cell distribution width was found significantly associated with advanced cIMT and with significant carotid artery stenosis (Furer et al. 2015) and white blood cell count with the presence of plaque (Halvorsen et al. 2009; Puz et al. 2013) and with cIMT measure (Willeit et al. 2016).

The white blood cell count in peripheral blood is usually increased in inflammatory and infectious conditions and could also be affected in plaque inflammation (Triantafllos et al. 2011). Higher leukocyte count is associated with a greater cardiovascular risk. In a meta-analysis of seven prospective studies comparing the top with the bottom third of the value distribution, the relative risk of coronary disease was 1.4 (95\% CI: 1.3-1.5)(Danesh et al. 1998), rendering leukocytes a valuable marker. The baseline neutrophil count was also related to a higher prevalence of echolucent plaques (Brevetti et al. 2008) and with the presence of microembolisms by transcranial Doppler examination (Jurk et al. 2010; Yin et al. 2017). Immunity system cells are thought to have a role in atherosclerosis development, as certain T-lymphocyte subtypes and total monocyte count were associated with an increased cIMT (Ammirati et al. 2012; Chapman et al. 2004; Puz et al. 2013). Innate immunity, driven by the monocyte-macrophage complex, may also represent a factor for developing and destabilization of the atheroma plaques (Bernelot Moens et al. 2017), and a significant correlation between plaque neovascularization and circulating levels of $\mathrm{CD} 14^{+} \mathrm{CD} 16^{-}$monocytes (Jaipersad et al. 2014) was also reported. When all data are considered, the relationship between levels of circulating activated monocytes and carotid artery stenosis remains controversial (Sternberg et al. 2013).

The formation of microvessels at the plaque has also been recognized as a contributing factor to destabilization and rupture. Levels of vascular endothelial growth factor (VEGF), were associated with the presence and severity of intracranial (but not extracranial) carotid stenosis (Yu et al. 2017) and inversely correlated with carotid plaque GSM (Heliopoulos et al. 2004; Sayed et al. 2009), predicting a higher presence of intraplaque neovessels as reported in histologic studies.

\section{ii. Fibrinogen and thrombosis-related biomarkers}

Fibrinogen is an acute-phase protein produced by the liver. Fibrinogen is a glycoprotein that circulates at a high concentration in blood and it is converted to fibrin to provide strength, flexibility and stability (Triantafllos et al. 2011). It can be used to assess cardiovascular risk in patients with atypical cardiovascular profile (Krobot et al. 1992). Fibrinogen increases plasma viscosity, increases blood coagulation (through increased fibrin and increased aggregation of platelets), increases inflammation (Stec et al. 2000). It has been shown that fibrinogen concentration is higher in people with cardiovascular system diseases compared to healthy people. In addition, it has been found that determining fibrinogen levels in the blood may be useful in assessing the risk of thrombosis. Higher levels of fibrinogen predicted subsequent acute coronary syndromes (ACS) while lower levels, despite elevated cholesterol levels, were associated with lower risk of ACS (Thompson et al. 1995). Elevated fibrinogen levels in patients with peripheral artery disease are associated with increased risk of fatal cardiovascular complications (Doweik et al. 2003). However, it remains unclear whether elevated fibrinogen levels are a cause or consequence of atherosclerosis. In the Copenhagen City Heart Study the relative risk of developing a stroke was almost double in patients with higher fibrinogen levels. Nevertheless they were not associated with echolucent unstable - and therefore vulnerable - carotid plaques (Kofoed et al. 2003).

Unstable carotid artery plaques express a wide array of thrombomodulatory factors. Only plasminogen activator inhibitor-1 (PAI-1) (a fibrinolysis inhibitor) serum levels showed a negative correlation with FDG uptake (the amount of radiotracer uptake) in the carotid artery (Rudd et al. 2009).

iii. Cellular adhesion proteins and endothelial microparticles

Cell adhesion molecules (CAMs) are a subset of cell surface proteins that are involved in the binding of cells with other cells or with the extracellular matrix (ECM), in a process called cell adhesion (Chothia and Jones 1997).

The selectins are a family of heterophilic CAMs that are dependent on fucosylated carbohydrates, e.g., 
mucins for binding. The three family members (E-selectin (endothelial), L-selectin (leukocyte), and P-selectin (platelet)) are involved in the rolling and anchoring of leukocytes on the vascular wall. Selectins have been implicated in several roles but they are especially important in the immune system by helping white blood cell homing and trafficking (Cavallaro and Christofori 2004). L-selectin is expressed on all granulocytes and monocytes and on most lymphocytes. It has been related to larger plaque size estimated by ultrasound imaging in patients with carotid atherosclerotic plaque (Andersson et al. 2009b). E-selectin levels significantly associated with carotid artery stenosis in patients who underwent carotid endarterectomy (Biscetti et al. 2015).

Vascular cell adhesion protein 1 (VCAM-1) also known as vascular cell adhesion molecule 1 or cluster of differentiation 106 is a CAM that in humans is encoded by the VCAM1 gene. VCAM-1 levels have been reported to be positively associated with cardiovascular mortality (Hoke et al. 2015), the presence of carotid atherosclerotic lesions (Debing et al. 2008), and MR markers of plaque instability (Shindo et al. 2014). Nevertheless VCAM-1 plasma concentration was not found to be correlated with the degree of stenosis (Debing et al. 2008) or with FDG uptake on PET imaging in the carotid artery (Duivenvoorden et al. 2013).

Intercellular Adhesion Molecule 1 (ICAM-1) also known as CD54 (Cluster of Differentiation 54) is a CAMs that in humans is encoded by the ICAM1 gene. There is evidence for a predictive role of circulating levels of ICAM-1 in initially healthy people as a significant association was observed with cardiovascular mortality (Hoke et al. 2015). ICAM-1 was found elevated in more than 300 patients who underwent carotid endarterectomy compared with healthy controls (Biscetti et al. 2015). Generally, expression of VCAM-1, ICAM-1, and L selectin has been consistently observed in atherosclerotic plaques and their soluble forms have been identified in the circulation (Blankenberg et al. 2003).

Endothelial microparticles (EMPs) are submicron particles $(0.1-1.0 \mathrm{~mm})$ released in response to endothelium cell activation or apoptosis promoting oxidative stress and vascular inflammation (Martinez et al. 2020). EMP concentrations were significantly higher in patients with carotid stenosis and in asymptomatic patients with unstable plaques compared with controls (Schiro et al. 2015). Certain specific EMP subsets, were higher in unstable plaques on histologic postoperative analysis in a cohort of patients undergoing endarterectomy (Wekesa et al. 2014).

\section{iv. Cytokines}

Many cytokines have been implicated in atheroma formation and complications. The quantities of IL-18 detected in patients with myocardial infarction or unstable angina were greater than in normal patients (Blankenberg et al. 2002). IL-18 has a bearing on the progression and stability of human atherosclerotic plaques (Mallat et al. 2001). Locally, within the atheroma, it also increases the expression of tissue factor, a potent thrombogenic protein (Taubman et al. 1997). Since IL-18 accentuates VCAM-1 and ICAM-1 levels, leukocyte adhesion is also increased as more IL-18 $\mathrm{s}$ are synthesized (Szmitko et al. 2003a, b).

Cytokines (IL-1, TNF- $\alpha$, and IL-6) prompt IL-18 gene expression in macrophages. IL-18 binds to its receptors expressed on lymphocytes (T-helper (Th) 1), ECs, SMCs, and macrophages (Xu et al. 1998) and primes the production of its activators (IL-1 $\beta$, TNF- $\alpha$ ) to establish a positive feedback mechanism that perpetuates inflammation and plaque formation.

Tumor necrosis factor $\alpha$ (TNF- $\alpha)$, also known as cachectin, is a major proinflammatory cytokine involved in atherosclerotic progression from the initial stages of intimal thickening to the subsequent vessel occlusion. It stimulates selectin and adhesion molecule expression and MMP -1-9, -11 and -13 production in the endothelium, VSMCs, and macrophages (Young et al. 2002). TNF- $\alpha$ is associated with a larger plaque size and has an inverse correlation with plaque grey scale median (GSM) estimated by ultrasound examination (Andersson et al. 2009a, 2009b). It is also increased in patients with plaque instability on nonsignificantly (Shindo et al. 2014) and significantly increased in symptomatic patients (Schneiderman et al. 2012).

Interleukin 6 (IL-6) is a master proinflammatory and procoagulant cytokine. IL- 6 enhances cell adhesion molecule expression and enhances the production of acute phase reactants such as CRP and TNF- $\alpha$ by the hepatocytes. Studies have confirmed the role of IL- 6 as an independent predictor of peripheral artery disease in community screening, irrespective of ethnicity (McDermott et al. 2005; Tzoulaki et al. 2006). Related to coronary artery events, it has also been reported elevated in patients bearing carotid atherosclerotic lesions and associated with cIMT (Chapman et al. 2004), but not with the degree of stenosis (Chapman et al. 2004; Debing et al. 2008; Puz et al. 2013). IL-6 may reflect local 
inflammatory activity, because it is upregulated in patients with plaque instability features on MR (Shindo et al. 2014), and increased in patients who underwent carotid endarterectomy (Biscetti et al. 2015) and in the debris retrieved from the cerebral embolic protection devices used during carotid artery stenting (Yang et al. 2016).

IL-1 $\beta$ is an important mediator of the inflammatory response involved in cell proliferation, differentiation, and apoptosis. Subcutaneous injection of canakinumab, a human monoclonal antibody that neutralizes IL-1 $\beta$, in patients with well-controlled diabetes mellitus and high cardiovascular risk, significantly decreased systemic inflammation (measured by levels of hsCRP and IL-6) without major effect on LDL or HDL (Ridker et al. 2012, 2018), supporting its significance as a mediator of atherosclerosis activity. IL- $1 \beta$ was also found independently and significantly associated with the presence of carotid artery stenosis in patients who underwent carotid endarterectomy (Biscetti et al. 2015).

Monocyte chemotactic protein 1 (also known as chemokine $\mathrm{C}-\mathrm{C}$ motif ligand-2) is one of the key chemokines that regulate migration and infiltration of monocytes and macrophages across vascular endothelium for routine immunological surveillance of tissues, as well as in response to inflammation (Martinez et al. 2020). Monocyte chemotactic protein 1 was found associated with carotid artery stenosis in patients who underwent carotid endarterectomy (Biscetti et al. 2015) and in patients with symptomatic carotid stenosis when compared with asymptomatic carotid stenosis (Grosse et al. 2016).

v. Protease activated receptor

High rates of Protease Activated Receptor (PAR) expression is induced by IL- 6 secretion in atherosclerotic lesions and areas of vascular tissue injury (Chi et al. 2001; Szmitko, et al. 2003a, b). IL-1 and TNF- $\alpha$ in inflamed cells also induce the proinflammatory property of PARs (Hansson 2005). PAR-1 activation in the endothelium facilitates the binding of monocytes when $\mathrm{NF}_{\kappa} \mathrm{B}$ is stimulated-a process that supports ICAM-1 expression (Dabbagh et al. 1998; Szmitko et al. 2003a, b). PAR-1 and PAR-2 release Weibel Palade bodies which contain p-secretin and von Willebrand factor, molecules that increase the adhesion of leukocytes and platelets to the endothelium (Hamilton et al. 2001; Szmitko et al. 2003a, b). Likewise, with PAR-3 serving as cofactor, PAR-1 activation promotes leukocyte recruitment in atherosclerosis (Szmitko et al. 2003a, b). PAR activity in SMC has been implicated in the translo- cation of SMCs from media to the intima and collagen synthesis: critical requirements for the formation of fibrous cap (Szmitko et al. 2003a, b).

vi. Circulating soluble CD40 ligand and urokinase plasminogen activator receptor

CD40 is a protein located on antigen presenting cells. CD40 receptor and its ligand, CD40L (on TH cells), have been detected in atherosclerotic plaques and found to be jointly expressed by activated macrophages, SMCs, vascular endothelial cells and T lymphocytes (Alvaro-González et al. 2002). Membrane-bound CD40L and sCD40L forms interact with the CD40 receptor molecule, leading to the release of matrix MMPs and subsequent destabilization of the plaque (André et al. 2002). Circulating soluble CD40 ligand (sCD40L), largely derived from activated platelets, activates an inflammatory reaction in vascular endothelial cells by the secretion of cytokines and chemokines. Elevated plasma concentrations of $\mathrm{sCD} 40 \mathrm{~L}$ at baseline predict a subsequent increased risk of future cardiovascular events in apparently healthy women and in anginastable patients (Triantafllos et al. 2011). Binding of sCD40L to CD40 on SMC and endothelium initiates a cascade of events that lead to endothelial dysfunction and inflammation through facilitation of the production of ROS, proinflammatory cytokines (IL-6, IL-1), VCAM-1, ICAM and MCP-1 (AlvaroGonzález et al. 2002; Szmitko et al. 2003a, b).

The soluble form of the cell-surface urokinase plasminogen activator receptor is released by endothelial and immune cells by proteolytic cleavage in an inflammatory environment. Plasma soluble urokinase plasminogen activator receptor (suPAR) is predictive of prevalent carotid and peripheral atherosclerosis and of incident events (Samman Tahhan et al. 2017). Levels were higher in patients with symptomatic carotid stenosis (Edsfeldt et al. 2012) and among symptomatic patients, higher in those with stroke or transient ischemic attack than in those with amaurosis fugax (Olson et al. 2010). These results may indicate that suPAR is a biomarker of the instability and severity of the thrombotic consequences of atheroma.

vii. Vascular calcification markers

Data derived from clinical studies support the notion that increased serum levels of the osteopontin (OPN), an acidic phosphoprotein, and osteoprotegerin (OPG), have emerged as novel markers of atherosclerotic plaque composition, are positively associated with acute cardiovascular events, coronary disease severity and poor long-term cardiovascular outcomes (Kiechl et al. 2004; Kurata 
et al. 2006). At present, only one study concerning pharmaceutical interventions with intensive lipidlowering therapy with statins has demonstrated the attenuation of serum OPN and OPG levels and enhanced carotid plaque echogenicity, and thereafter stability, in patients with carotid stenosis (NPE Kadoglou et al. 2008). Circulating OPG levels were higher in patients bearing carotid stenosis (Davaine et al. 2014) with unstable atherosclerotic plaques (Straface et al. 2011) and in symptomatic vs asymptomatic patients (who showed greater calcification)(Schiro et al. 2015). Patients with echogenic plaques had lower OPG levels in a healthy population report (Vik et al. 2007), but higher in other studies (NPE Kadoglou et al. 2008).

\section{viii. Matrix metalloproteinases}

Matrix metalloproteinases (MMPs) are a class of zincdependent endopeptidases with proteolytic activity toward one or more components of the extracellular matrix that may be involved in the process of plaque destabilization and cap erosion (Halim and Newby 2009; Kadoglou and Liapis 2004). An imbalance between these enzymes and their inhibitors (tissue inhibitors of metalloproteinases may lead to matrix degradation and plaque destabilization. At the initial stages of atherogenesis, MMPs have been also hypothesized to mediate subintimal inflammatory cell infiltration (Dorweiler et al. 2008). Therefore, degenerative proteases seem to additionally promote lipid-necrotic core formation in the atherosclerotic plaque.

Histopathological studies and experimental models have revealed overproductions of MMPs in the rupture-prone regions of atherosclerotic plaques. Histological analysis of specimens obtained from patients with unstable angina has demonstrated a remarkable increase in intracellular MMP-9 levels than those with stable angina. Studies have confirmed MMP-9 plasma concentrations predicted stroke and cardiovascular death in patients with $\geq 50 \%$ carotid stenosis, although not independently (Eldrup et al. 2006; Jefferis et al. 2010). The positive predictive value of MMP-9 was significantly enhanced when combined with other members of the MMP family (MMP-7, MMP-8 and MMP-12 and their tissue inhibitor TIMP-1)(Jiang et al. 2004; NP Kadoglou and Liapis 2004) or with plaque echolucency (NP Kadoglou et al. 2005). Carotid plaques from surgery samples were also analyzed histologically and features of instability were found in patients with higher serum levels of tissue inhibitor of matrix protease 1, MMP-1, and MMP-7 (Pelisek et al. 2009). MMP-7 was also ele- vated in the sera of patients who had a stroke 2 to 6 months before (Cheng et al. 2009). MMP-9 levels were higher in patients with active carotid plaques at PET imaging (Rudd et al. 2009) and symptomatic patients submitted to carotid endarterectomy showed higher serum levels of MMP-2 and MMP-9 (Alvarez et al. 2004). Additionally, elevated levels of MMP-9 were found in the debris retrieved from the cerebral embolic protection devices used during carotid artery stenting (Yang et al. 2016).

\section{ix. Myeloperoxidase}

Myeloperoxidase (MPO) is a hemoprotein produced by polymorphonuclear neutrophils and macrophages and involved in the oxidation of lipids contained within LDL particles, and is thought to promote the formation of foam cells in atherosclerotic plaques (Podrez et al. 1999). Together with MMPs, MPO degrades the collagen layer of atheroma leading to erosion or rupture of plaques and its fatal consequences (Naruko et al. 2002). MPO has been proposed as a marker of plaque instability even if it is not specific to cardiac diseases, as activation of neutrophils and macrophages can occur in infectious, inflammatory or infiltrative disease processes (Triantafllos et al. 2011).

\section{$\mathrm{x}$. Lipid biomarkers}

Lipid factors are, together with inflammatory factors, the main actors in the onset, evolution and destabilization of the atheroma plaque, although their role and specific functions remain to be fully understood.

There is compelling evidence on the cardiovascular benefits of LDL cholesterol (LDL-c) lowering, mostly by decreasing the availability of cholesterol particles able to enter the endothelium at the earliest stage of atherosclerosis (Martinez et al. 2020). However, the notion of residual cardiovascular risk recently emerged in patients treated with statins, even after achieving a significant LDL-c reduction, caused by the atherogenic effects of triglyceride-rich lipoproteins (TRLs), particularly the very low-density lipoproteins (VLDL). This finding prompted the use of the concept of non-HDL cholesterol, which reflects cholesterol in all atherogenic particles containing Apo B (LDL-c + VLDL$\mathrm{c}+$ lipoprotein $(\mathrm{a})+$ cholesterol remnants). In this regard, non-HDL cholesterol might outperform LDL-C as a lipid marker of cardiovascular risk, in particular in patients with atherogenic dyslipidemia (Millán et al. 2016). Recently, however, LDL-c, even at normal levels, was found to be independently associated with the presence and extent of early systemic atherosclerosis in the absence 
of major cardiovascular risk factors (FernándezFriera et al. 2017). LDL-c also comprises multiple distinct subfractions, which can be separated by ultracentrifugation, gradient gel electrophoresis or nuclear MR. In contrast to large LDL-c particles, small and dense LDL-c particles have a greater atherogenic potential owing to decreased clearance, greater binding, increased penetrability, and susceptibility to oxidative modification (Martinez et al. 2020). Small and dense LDL-c particles have been associated with coronary heart disease and with carotid atherosclerosis (St-Pierre et al. 2005). Higher plasma levels also independently predicted an increased cIMT and associated proinflammatory activation of peripheral mononuclear cells and endothelial cells in patients with carotid atherosclerosis (Norata et al. 2009).

Oxysterols are oxidized end products of cholesterol metabolism. Their production is enhanced by certain risks factors like tobacco exposure or overuse of frying oil, which produce oxidizing free radicals. Oxysterols are cytotoxic to cells by inducing apoptosis, stimulating the formation of foam cells, and contributing to plaque vulnerability by inducing the upregulation of MMP-9 in macrophages (Vaya 2013). The oxidized LDL cholesterol (ox-LDL-c) plasma levels are inversely correlated with carotid plaque GSM, indicating that lipid peroxidation and reduced antioxidant capacity result in more vulnerable carotid plaques (Andersson et al. 2009a, b; Nishi et al. 2002).

Lectin-like oxidized low-density lipoprotein receptor-1 (LOX-1), expressed in endothelial cells, macrophages and SMCs, recognizes and binds specifically to oxidized low-density lipoprotein (oxLDL), apoptotic cells, activated platelets, advanced glycation end products, and pathogenic organism (Chen et al. 2002). LOX-1 provides a route of entry for oxLDL into endothelium, an action that disrupts normal endothelial function by encouraging monocyte adhesion and infiltration (Boamponsem and Boamponsem 2011). The oxLDL/LOX-1 complex enhances ROS production, death of SMCs and MMP influence on fibrous cap (Li et al. 2003; Szmitko et al. 2003a, b).

High-density lipoprotein cholesterol (HDL-c) protects the vessel wall against plaque progression, inducing the transformation of plaque mass to a higher echogenicity, through the reduction of lipid content and inflammation (Johnsen et al. 2005). Epidemiologic studies have proved the association of HDL-c levels and cIMT (Touboul et al. 2014). Low levels of HDL-c and higher total cholesterol/HDL-c ratios were associated with lower GSM and other characteristics of carotid plaque instability (Mathiesen et al. 2001; Peters et al. 2012). In a similar fashion to low-density lipoprotein cholesterol (LDL-c), HDL-c particle sizes do matter: an HDL size of greater than $8.22 \mathrm{~nm}$ was independently associated with low cIMT (Parra et al. 2014) and there was an inverse association between the serum HDL3-cholesterol (HDL3-c) (smaller molecules) and plaque area and a positive association between serum HDL2-cholesterol (HDL2-c)(larger and most effective in cholesterol removal) and plaque thickness (Tiozzo et al. 2014).

Triglyceride-Rich Lipoproteins (TRLs) are a pool of lipoproteins that include chylomicrons, VLDL, intermediate-density lipoproteins (IDL), and other remnant lipid metabolism particles (Martinez et al. 2020). They can predict increased cIMT and are associated with a proinflammatory activation of peripheral mononuclear cells and endothelial cells (Norata et al. 2009). Elevated TRL levels have been identified as an independent risk factor for future ischemic strokes and for echolucent carotid plaques (Kofoed et al. 2002; Nakamura et al. 2009).

Lipoprotein phospholipase $\mathrm{A}_{2}\left(\mathrm{Lp}-\mathrm{LPA}_{2}\right)$ travels along with circulating LDL-c and induces a proinflammatory reaction in the vessel. Its levels are higher at shoulder and necrotic lipid core areas of histology samples (Mannheim et al. 2008). Lipoproteinassociated phospholipase (LpPLA $\mathrm{L}_{2}$ ), expressed by human atherosclerotic lesions, has proinflammatory and proatherogenic functions by generating lysophosphatidylcholine (lysoPC) and non-esterified fatty acid moieties (MacPhee et al. 1999). LysoPC promotes monocyte chemotaxis and increases expression of mononuclear leukocyte adhesion molecules in endothelial cells. LysoPC is suspected to facilitate initiation of atherosclerotic lesion through such activities by binding to peptides and become antigenic and in turn, stimulate $\mathrm{T}$ cells (Szmitko et al. 2003a, b). Secretory PLA 2 levels, but not Lp-PLA2 levels, have been associated with atherosclerotic plaques and outcome (Lind et al. 2012). Interestingly, however, circulating Lp$\mathrm{PLA}_{2}$ was found to be increased in patients with high-grade carotid stenosis and unstable plaques in a small series of patients undergoing endarterectomy (Sarlon-Bartoli et al. 2012).

Lipoprotein (a) (Lp(a)) is an LDL-like particle, rich in cholesterol and strongly influenced by genetic background. Elevated levels are associated with an increased risk for cardiovascular diseases (Kassner et al. 2015; Rigamonti et al. 2018), but not carotid 
atherosclerosis in a group of patients with statintreated familial hyperlipidemia (Bos et al. 2015). Other studies reported increased levels of $\mathrm{Lp}(\mathrm{a})$ in patients with high-grade unstable carotid stenosis and a strong correlation with hypoechoic plaques (Iwamoto et al. 2004). Lp(a) apheresis resulted in cIMT and plaque reduction (Ezhov et al. 2015; Pokrovsky et al. 2017), but, although Lp(a) independently predicted carotid stenosis and occlusion, it was not related with plaque area in another study (Klein et al. 2008).

Apolipoproteins (Apos) are the protein components of plasma lipoproteins, which consist of a core of triglyceride and cholesterol esters and a peripheral region of phospholipid, sphingolipid and protein (Martinez et al. 2020). The most relevant subtypes are Apo A-I (the main protein on HDL), Apo B-100 (the main protein on LDL), Apo C-II (important in chylomicrons and VLDL, activates lipoprotein lipase), and Apo E (present in chylomicrons, VLDL, and IDL, allowing the binding of these lipoproteins to the hepatocytes). ApoA-I (or ApoA1) is considered an atheroprotective biomarker for its relation with HDL-c (Martinez et al. 2020). AntiApoA-I immunoglobulin G levels were independently associated with cardiovascular disease in the general population and also related to cardiovascular biomarkers in secondary prevention in a recent cross-sectional population study with more than 6000 patients (Antiochos et al. 2016). A meta-analysis including eight cohort and four case-control studies concluded that reduced ApoA-I, increased ApoB levels, and the ApoB/A-I ratio were risk factors for a first ischemic but not hemorrhagic stroke (Dong et al. 2015). This conclusion is supported by a clinical study where ApoA-I levels were lower in ischemic stroke cases vs controls (Walsh et al. 2016). ApoB, which constitutes the gross majority of Apos found in LDL, is considered atheroprone, as reported in a meta-analysis (Dong et al. 2015), although no significant correlation with major cardiovascular events was found in a large cohort study (van den Berg et al. 2016). The existence of two allele proteins (ApoB100 and ApoB48), might bias these findings, and no report of specific determination of ApoB100 related to carotid atherosclerosis has been published as yet. ApoE presence is high among TRLs such as VLDL and IDL. A large meta-analysis of 22 studies including 30,879 participants demonstrated a significant association between APOE genotype and cIMT (Paternoster et al. 2008) and a positive dose-response association with LDL-c, cIMT, and ischemic stroke was proven in another large meta-analysis (Khan et al. 2013). In contrast, no evidence of an association of circulating ApoE concentration with cardiovascular events was found in a patient cohort including more than 9000 participants, with the authors concluding that these results may be explained by isoform-specific functions (Sofat et al. 2016).

Serum amyloid-A protein (SAA) is an acute phase apolipoprotein related to high-density lipoprotein (HDL). Levels of greater than $10 \mathrm{mg} / \mathrm{L}$ were significantly associated with a greater number of new cerebral lesions detected on diffusion weighted MR imaging during carotid artery stenting (Pini et al. 2013) and significantly associated with progressive atherosclerosis measured by ultrasound examination (Schillinger et al. 2005). Higher levels can identify patients with ischemic stroke caused by atherothrombosis vs cardioembolic stroke (Brea et al. 2009).

\section{xi. Metabolic biomarkers}

Adipokine is the term used to name cytokines (cell signaling proteins) secreted by adipocytes. Resistin is involved in glucose and lipid homeostasis. As a marker of an altered metabolic status, levels were significantly higher in symptomatic than in asymptomatic subjects submitted to carotid endarterectomy (Gasbarrino et al. 2016b). Adiponectin is also related to systemic inflammation and metabolic disease, probably by interaction with cHDL efflux capacity (the ability of HDL to accept cholesterol from macrophages, a key step in reverse cholesterol transport)(Marsche et al. 2017). Its relation with cIMT is inconclusive: some studies found a positive correlation (Iglseder et al. 2005; Persson et al. 2015), although a meta-analysis including 55 studies suggested an inconclusive inverse association (Gasbarrino et al. 2016a). In a systematic review of 12 studies, circulating levels of adiponectin predicted a higher risk for ischemic stroke (Gorgui et al. 2017), suggesting an instability-promoting role. Conflicting with these findings, adiponectin levels have been found positively associated with plaque GSM (indicating a more stable, lower fat content plaque) (Gustafsson et al. 2010). Fatty acid binding protein 4 plays an important role in the development of insulin resistance and atherosclerosis in relation to inflammation (Furuhashi et al. 2014). High levels have been found in patients with carotid atherosclerosis, compared with patients having suffered a noncarotid-related stroke (Holm et al. 2011).

Homocysteine is well-documented as a biomarker for cardiovascular diseases. In the carotid setting, high levels were associated with carotid plaque morphology and total carotid plaque area measured by Doppler 
ultrasound examination (Alsulaimani et al. 2013) and is also correlated with restenosis after carotid endarterectomy (Alvarez et al. 2012). A recent study including 5393 participants older than 40 years and free of previous cardiovascular events showed that individuals with asymptomatic carotid artery stenosis had higher homocysteine levels (Jia et al. 2016). Very interestingly, in a retrospective analysis of patients submitted to carotid endarterectomy for asymptomatic carotid stenosis, higher homocysteine levels identified a cohort for whom intensive medical therapy alone appeared to be the preferred option (Duschek et al. 2013).

Bilirubin is a potent antioxidant that has been inversely related to cardiovascular disease, cIMT (Hamur et al. 2016), carotid plaque burden (Amor et al. 2017), and hsCRP levels (Zheng et al. 2016). Lower levels of bilirubin correlated with silent cerebral infarction on cerebral MR, which may precede symptomatic ischemic events ( $\mathrm{Li}$ et al. 2014).

Small regulatory RNA strands called micro-RNA have been related to atherosclerosis recently in both cellular and animal models. A huge variety of such molecules have been identified, and certain types may work as serum biomarkers of human atherosclerosis and carotid plaque (Dolz et al. 2017; Maitrias et al. 2017), but their potential in stroke prevention requires further investigation (Martinez et al. 2020).

\section{Conclusions}

Atherosclerosis is characterized by a complex endocrine, paracrine, and juxtacrine cross-talk between immune and vascular cells as well as several tissues and organs. Several factors are seen to contribute to the genesis of atherosclerosis. The earliest vascular change described microscopically, intimal thickening, consists of layers of smooth muscle cells and extracellular matrix. Most of the biomarkers associated with atherosclerosis are indicators of inflammatory response. There was an up-regulation of CRP and complement protein levels in plaque tissues with elevated fibrinogen and leukocyte count levels are associated with a greater cardiovascular risk. Many cytokines have been also implicated. PAR activation also plays a role in the process of atherosclerosis. The elevated plasma concentrations of $\mathrm{SCD} 40 \mathrm{~L}$ at baseline as well as the OPN, an acidic phosphoprotein, and OPG are also positively associated with poor long-term cardiovascular outcomes. Together with MMPs, MPO degrades the collagen layer of atheroma leading to erosion or rupture of plaques and its fatal consequences. The oxLDL/LOX-1 complex enhances ROS production, death of SMCs, and MMP influence on fibrous cap. LpPLA ${ }_{2}$ also expressed by human atherosclerotic lesions.

\section{Abbreviations}

ACAT1: Acetyl-CoA acetyltransferase 1; ACS: Acute coronary syndromes; AHA: American Heart Association; CIMT: Carotid Intima-Media Thickness Test; CD40: Cluster of differentiation 40; CD40L: CD40 ligand; CRP: C reactive protein; ECs: Endothelial cells; ICAM: Intercellular cell adhesion molecule; LDL: Low density lipoprotein; LpPLA 2 : Lipoprotein-associated phospholipase $A_{2}$; Lox-1: Lectinlike oxidized low density lipoprotein receptor-1; MMPs: Matrix metalloproteinases; MPO: Myeloperoxidase; OxLDL: Oxidized low-density lipoprotein; PAR: Protease activated receptor; PIT: Pathologic intimal thickening; ROS: Reactive oxygen species; sCD40L: Circulating soluble CD40 ligand; SMC: Smooth muscle cell; TNF: Tumor necrosis factor; VCAM-1: Vascular cell adhesion molecule 1; VSMCs: Vascular smooth muscle cells.

\section{Acknowledgements}

Authors are grateful to College of Health Sciences Research and Community Office of Arsi University as well as researchers who their documents were used in the preparation of the review.

\section{Authors' contributions}

LM and AD had participated in the design of the study, data analyses, and manuscript preparation; and the authors could have read and approved the final manuscript.

\section{Funding}

Nil support in financial or other manner.

Availability of data and material

The datasets used and analyzed during the current study are available from the corresponding author on reasonable request.

\section{Declarations}

Ethics approval and consent to participate

Not applicable.

Consent for publication

Not applicable.

\section{Competing interests}

The authors declare that there is no conflict of interests regarding the publication of this paper.

\section{Author details \\ ${ }^{1}$ Department of Biomedical Sciences, College of Health Sciences, Arsi University, Asella, Oromia, Ethiopia. ${ }^{2}$ Department of Clinical Nursing, College of Health Sciences, Arsi University, Asella, Oromia, Ethiopia.}

Received: 23 September 2021 Accepted: 11 December 2021 Published online: 20 December 2021

\section{References}

Alexander R, Dzau V (2000) Vascular biology: the past 50 years. Circulation 102: IV-112-IV-116

Alsulaimani S, Gardener H, Elkind M, Cheung K, Sacco R, Rundek T (2013) Elevated homocysteine and carotid plaque area and densitometry in the northern Manhattan study. Stroke 44:457-461

Alvarez B, Ruiz C, Chacon P, Alvarez-Sabin J, Matas M (2004) Serum values of metalloproteinase-2 and metalloproteinase- 9 as related to unstable plaque and inflammatory cells in patients with greater than $70 \%$ carotid artery stenosis. J Vasc Surg 40:469-475

Alvarez B, Yugueros X, Fernandez E, Luccini F, Gene A, Matas M (2012) Relationship between plasma homocysteine and the morphological and immunohistochemical study of carotid plaques in patients with carotid stenosis over 70\%. Ann Vasc Surg 26:500-505

Alvaro-González L, Freijo-Guerrero M, Sádaba-Garay F (2002) Inflammatory mechanisms, arteriosclerosis and ischemic stroke: clinical data and perspectives. Rev Neurol 35:452-462 
Ammirati E, Cianflone D, Vecchio V, Banfi M, Vermi A, De Metrio M, Grigore L, Pellegatta F (2012) Effector memory T cells are associated with atherosclerosis in humans and animal models. J Am Heart Assoc 1:27-41

Amor A, Ortega E, Perea V, Cofán M, Sala-Vila A, Nuñez I, Gilabert R, Ros E (2017) Relationship between total serum bilirubin levels and carotid and femoral atherosclerosis in familial dyslipidemia highlights. Arterioscler Thromb Vasc Biol 37:2356-2363

Andersson J, Sundström J, Gustavsson T, Hulthe J, Elmgren A, Zilmer K, Zilmer M, Lind L (2009a) Echogenicity of the carotid intima-media complex is related to cardiovascular risk factors, dyslipidemia, oxidative stress and inflammation: the Prospective Investigation of the Vasculature in Uppsala Seniors (PIVUS) study. Atherosclerosis 204:612-618

Andersson J, Sundström J, Kurland L, Gustavsson T, Hulthe J, Elmgren A, Zilmer K, Zilmer M (2009b) The carotid artery plaque size and echogenicity are related to different cardiovascular risk factors in the elderly: the Prospective Investigation of the Vasculature in Uppsala Seniors (PIVUS) study. Lipids 44:397-403

André P, Nannizzi-Alaimo L, Prasad S, Phillips D (2002) Platelet derived CD40L. The switch hitting player of cardiovascular disease. Circulation 106:896-899

Antiochos P, Marques-Vidal P, Virzi J, Pagano S, Satta N, Bastardot F, Hartley O, Montecucco F (2016) Association between anti-apolipoprotein A-1 antibodies and cardiovascular disease in the general population. Results from the CoLaus study. Thromb Haemost 116:764-771

Armstrong M, Heistad D, Megan M, Lopez J, Harrison D (1990) Reversibility of atherosclerosis. Cardiovasc Clin 20:113-126

Badimon L, Storey R, Vilahur G (2012) Update on lipids, inflammation and atherothrombosis. Thromb Haemost 105:S34-S42

Badimon L, Vilahur G (2014) Thrombosis formation on atherosclerotic lesions and plaque rupture (Review). J Intern Med 276:618-632

Bao L, Li Y, Deng S, Landry D, Tabas I (2006) Sitosterol containing lipoproteins trigger free sterol-induced caspaseindependent death in ACATcompetent macrophages. J Biol Chem 281:33635-33649

Baragetti A, Knoflach M, Cuccovillo I, Grigore L, Casula M, Garlaschelli K, Mantovani A, Wick G (2014) Pentraxin 3 (PTX3) plasma levels and carotid intima media thickness progression in the general population. Nutr Metab Cardiovasc Dis 24:518-523

Bentzon J, Otsuka F, Virmani R, Falk E (2014) Mechanisms of plaque formation and rupture. Circ Res 114:1852-1866

Bernelot Moens S, Verweij S, Schnitzler J, Stiekema L, Bos M, Langsted A, Kuijk C, Bekkering S (2017) Remnant cholesterol elicits arterial wall inflammation and a multilevel cellular immune response in humans. Arterioscler Thromb Vasc Biol 37:969-975

Biscetti F, Straface G, Bertoletti G, Vincenzoni C, Snider F, Arena V, Landolfi R, Flex A (2015) Identification of a potential proinflammatory genetic profile influencing carotid plaque vulnerability. J Vasc Surg 61:374-381

Blankenberg S, Barbaux S, Tiret L (2003) Adhesion molecules and atherosclerosis. Atherosclerosis 170:191-203

Blankenberg S, Tiret L, Bickel C, Peetz D, Cambien F, Meyer J, Rupprecht H (2002) Interleukin-18 is a strong predictor of cardiovascular death in stable and unstable angina. Circulation 106:24-30

Boamponsem A, Boamponsem L (2011) The Role of Inflammation in Atherosclerosis. Adv Appl Sci Res 2:194-207

Bonacina F, Baragetti A, Catapano A, Norata G (2013) Long pentraxin 3: experimental and clinical relevance in cardiovascular diseases. Mediators Inflamm 725102

Bos S, Duvekot M, Touw-Blommesteijn A, Verhoeven A, Mulder M, Watts G, Sijbrands E, Roeters van Lennep J (2015) Lipoprotein (a) levels are not associated with carotid plaques and carotid intima media thickness in statin-treated patients with familial hypercholesterolemia. Atherosclerosis 242:226-229

Brea D, Sobrino T, Blanco M, Fraga M, Agulla J, Rodríguez-Yáñez M, Pérez de la Ossa N, Leira R (2009) Usefulness of haptoglobin and serum amyloid A proteins as biomarkers for atherothrombotic ischemic stroke diagnosis confirmation. Atherosclerosis 205:561-567

Brevetti G, Sirico G, Lanero S, De Maio J, Laurenzano E, Giugliano G (2008) The prevalence of hypoechoic carotid plaques is greater in peripheral than in coronary artery disease and is related to the neutrophil count. J Vasc Surg 47:523-529
Burke A, Farb A, Malcom G, Liang Y, Smialek J, Virmani R (1998) Effect of risk factors on the mechanism of acute thrombosis and sudden coronary death in women. Circulation 97:2110-2116

Burke A, Farb A, Malcom G, Liang Y, Smialek J, Virmani R (1997) Coronary risk factors and plaque morphology in men with coronary disease who died suddenly. N Engl J Med 336:1276-1282

Cavallaro U, Christofori G (2004) Cell adhesion and signalling by cadherins and Ig-CAMs in cancer. Nat Rev Cancer 4:118-132

Chapman C, Beilby J, McQuillan B, Thompson P, Hung J (2004) Monocyte count, but not c-reactive protein or interleukin-6, is an independent risk marker for subclinical carotid atherosclerosis. Stroke 35:1619-1624

Chen M, Masaki T, Sawamura T (2002) LOX-1, the receptor for oxidized lowdensity lipoprotein identified from endothelial cells: implications in endothelial dysfunction and atherosclerosis. Pharmacol Ther 95:89-100

Cheng C, Tempel D, van Haperen R, van Damme L, Algür M, Krams R, de Crom R (2009) Activation of MMP8 and MMP13 by angiotensin II correlates to severe intra-plaque hemorrhages and collagen breakdown in atherosclerotic lesions with a vulnerable phenotype. Atherosclerosis 204:26-33

Chi L, Li Y, Stehno-Bittel L, Gao J, Morrison D, Stechschulte D, Dileepan K (2001) Interleukin-6 production by endothelial cells via stimulation of protease-activated receptors is amplified by endotoxin and tumor necrosis factor-alpha. J Interferon Cytokine Res 21:231-240

Chothia C, Jones E (1997) The molecular structure of cell adhesion molecules. Annu Rev Biochem 66:823-862

Collins R, Armitage J, Parish S, Sleigh P, Peto R, Heart Protection Study Collaborative Group (2003) MRC/BHF Heart Protection Study of cholesterollowering with simvastatin in 5963 people with diabetes: a randomised placebo-controlled trial. Lancet 361:2005-2016

Dabbagh K, Laurent G, McAnulty R, Chambers R (1998) Thrombin stimulates smooth muscle cell procollagen synthesis and mRNA levels via a PAR-1 mediated mechanism. Thromb Haemost 79:405-409

Danesh J, Collins R, Appleby P, Peto R (1998) Association of fibrinogen, C-reactive protein, albumin, or leukocyte count with coronary heart disease: meta-analyses of prospective studies. JAMA 279:1477-1482

Davaine J, Quillard T, Brion R, Lapérine O, Guyomarch B, Merlini T, Chatelais M, Guilbaud F (2014) Osteoprotegerin, pericytes and bone-like vascular calcification are associated with carotid plaque stability. PLOS ONE 9:e107642

Davies M, Woolf N, Rowles P, Pepper J (1988) Morphology of the endothelium over atherosclerotic plaques in human coronary arteries. Br Heart J 60:459-464

de Feyter P, Ozaki Y, Baptista J, Escaned J, Di Mario C, de Jaegere P, Serruys P, Roelandt J (1995) Ischemia-related lesion characteristics in patients with stable or unstable angina: a study with intracoronary angioscopy and ultrasound. Circulation 92:1408-1413

Debing E, Peeters E, Demanet C, De Waele M, Van den Brande P (2008) Markers of inflammation in patients with symptomatic and asymptomatic carotid artery stenosis: a case-control study. Vasc Endovascular Surg 42:122-127

Defraigne J (2007) Pathophysiology of atherosclerosis. In: Vascular Surgery, European Manual of Medicine Series. Springer-Verlag, Berlin, Heidelberg

Dolz S, Górriz D, Tembl J, Sánchez D, Fortea G, Parkhutik V, Lago A (2017) Circulating MicroRNAs as novel biomarkers of stenosis progression in asymptomatic carotid stenosis. Stroke 48:10-16

Dong H, Chen W, Wang X, Pi F, Wu Y, Pang S, Xie Y, Xia F (2015) Apolipoprotein $A 1, B$ levels, and their ratio and the risk of a first stroke: a meta-analysis and case-control study. Metab Brain Dis 30:1319-1330

Dorweiler B, Torzewski M, Dahm M, Kirkpatrick C, Lackner K, Vahl F (2008) Subendothelial infltration of neutrophil granulocytes and liberation of matrixdestabilizing enzymes in an experimental model of human neointima. Thromb Haemost 99:373-381

Dos Santos V, Pozzan G, Castelli V, Caffaro R (2021) Arteriosclerosis, atherosclerosis, arteriolosclerosis, and Monckeberg medial calcific sclerosis: what is the difference? J Vasc Bras 20:e20200211

Doweik L, Maca T, Schillinger M, Budinsky A, Sabeti S, Minar E (2003) Fibrinogen predicts mortality in high risk patients with peripheral artery disease. Eur J Vasc Endovasc Surg 26:381-386

Duivenvoorden R, Mani V, Woodward M, Kallend D, Suchankova G, Fuster V, Rudd J, Tawakol A (2013) Relationship of serum inflammatory 
biomarkers with plaque inflammation assessed by FDG PET/CT: The dal-PLAQUE study. JACC Cardiovasc Imaging 6:1087-1094

Duschek N, Ghai S, Sejkic F, Falkensammer J, Skrinjar E, Huber K, Wojta J, Waldhör T (2013) Homocysteine improves risk stratification in patients undergoing endarterectomy for asymptomatic internal carotid artery stenosis. Stroke 44:2311-2314

Edsfeldt A, Nitulescu M, Grufman H, Grönberg C, Persson A, Nilsson M, Persson M, Björkbacka H (2012) Soluble urokinase plasminogen activator receptor is associated with inflammation in the vulnerable human atherosclerotic plaque. Stroke 43:3305-3312

Eldrup N, Gronholdt M, Sillesen H, Nordestgaard B (2006) Elevated matrix metalloproteinase-9 associated with stroke or cardiovascular death in patients with carotid stenosis. Circulation 114:1847-1854

Eltoft A, Arntzen K, Hansen J, Wilsgaard T, Mathiesen E, Johnsen S (2017) C-reactive protein in atherosclerosisda risk marker but not a causal factor? A 13-year population-based longitudinal study: the Tromsø study. Atherosclerosis 263:293-300

Ezhov M, Safarova M, Afanasieva O, Pogorelova O, Tripoten M, Adamova I, Konovalov G, Balakhonova T (2015) Specific Lipoprotein(a) apheresis attenuates progression of carotid intima-media thickness in coronary heart disease patients with high lipoprotein(a) levels. Atheroscler Suppl 18:163-169

Farb A, Burke A, Tang A, Liang T, Mannan P, Smialek J, Virmani R (1996) Coronary plaque erosion without rupture into a lipid core: a frequent cause of coronary thrombosis in sudden coronary death. Circulation 93:1354-1136

Fernández-Friera L, Fuster V, López-Melgar B, Oliva B, García-Ruiz J, Mendiguren J, Bueno H, Pocock S (2017) Normal LDL-cholesterol levels are associated with subclinical atherosclerosis in the absence of risk factors. J Am Coll Cardiol 70:2979-2991

Fernández-Friera L, Peñalvo J, Fernández-Ortiz A, Ibañez B, López-Melgar B, Laclaustra M, Oliva B, Mocoroa A, Mendiguren J (2015) Prevalence, Vascular Distribution, and Multiterritorial Extent of Subclinical Atherosclerosis in a Middle-Aged Cohort: The PESA (Progression of Early Subclinical Atherosclerosis) Study. Circulation 131:2104-2113

Finn A, Nakano M, Narula J, Kolodgie F, Virmani R (2010) Concept of vulnerable/Unstable plaque. Arterioscler Thromb Vasc Biol 30:1282-1292

Fishbein M, Siegel R (1996) How big are coronary atherosclerotic plaques that rupture? Circulation 94:2662-2666

Furer A, Finkelstein A, Halkin A, Revivo M, Zuzut M, Berliner S, Herz I, Solodukhin A (2015) High red blood cell distribution width and preclinical carotid atherosclerosis. Biomarkers 20:376-381

Furuhashi M, Saitoh S, Shimamoto K, Miura T (2014) Fatty acidbinding protein 4 (FABP4): pathophysiological insights and potent clinical biomarker of metabolic and cardiovascular diseases. Clin Med Insights Cardiol $8: 23-33$

Gasbarrino K, Gorgui J, Nauche B, Côté R, Daskalopoulou S (2016a) Circulating adiponectin and carotid intima-media thickness: a systematic review and metaanalysis. Metabolism 65:968-986

Gasbarrino K, Mantzoros C, Gorgui J, Veinot J, Lai C, Daskalopoulou S (2016b) Circulating chemerin is associated with carotid plaque instability, whereas resistin is related to cerebrovascular symptomatology. Arterioscler Thromb Vasc Biol 36:1670-1678

Glass C, Witztum J (2001) Atherosclerosis: the road ahead. Cell 104:503-516 Goff D, Lloyd-Jones D, Bennett G, Coady S, D'Agostino R, Gibbons R, Greenland P, Lackland D, Levy D (2014) 2013 ACC/AHA guideline on the assessment of cardiovascular risk: a report of the American College of Cardiology/American Heart Association Task Force on Practice Guidelines. Circulation 129:S49-S73

Gorgui J, Gasbarrino K, Georgakis M, Karalexi M, Nauche B, Petridou E, Daskalopoulou S (2017) Circulating adiponectin levels in relation to carotid atherosclerotic plaque presence, ischemic stroke risk, and mortality: a systematic review and meta-analyses. Metabolism 69:51-66

Grønholdt M, Sillesen H, Wiebe B, Laursen H, Nordestgaard B (2001) Increased acute phase reactants are associated with levels of lipoproteins and increased carotid plaque volume. Eur J Vasc Endovasc Surg 21:227-234

Grosse G, Schulz-Schaeffer W, Teebken O, Schuppner R, Dirks M, Worthmann H, Lichtinghagen R, Maye G (2016) Monocyte subsets and related chemokines in carotid artery stenosis and ischemic stroke. Int J Mol Sci $17: 433$
Gustafsson S, Lind L, Söderberg S, Ingelsson E (2010) Associations of circulating adiponectin with measures of vascular function and morphology. J Clin Endocrinol Metab 95:2927-2934

Halim S, Newby L (2009) Prognostic biomarkers in individuals with prevalent coronary heart disease. Dis Markers 26:265-271

Halvorsen D, Johnsen S, Mathiesen E, Njølstad I (2009) The Association between inflammatory markers and carotid atherosclerosis is sex dependent: the Tromsø Study. Cerebrovasc Dis 27:392-397

Hamilton J, Frauman A, CocksT, (2001) Increased expression of proteaseactivated receptor-2 (PAR2) and PAR4 in human coronary artery by inflammatory stimuli unveils endothelium-dependent relaxations to PAR2 and PAR4 agonists. Circ Res 89:92-98

Hamur H, Duman H, Demirtas L, Bakirci E, Durakoglugil M, Degirmenci H, Kalkan K, Yildirim E (2016) Total bilirubin levels predict subclinical atherosclerosis in patients with prediabetes. Angiology 67:909-915

Hansson G (2005) Inflammation, atherosclerosis, and coronary artery disease. N Engl J Med 352:1685-1695

Heliopoulos I, Papazoglou D, Piperidou H, Vadikolias K, Maltezos E, Artemis N (2004) Carotid plaque echomorphology and serum vascular endothelial growth factor levels. Eur Neurol 51:104-108

Hoke M, Winter M, Wagner O, Exner M, Schillinger M, Arnold Z, Mlekusch W, Maurer G (2015) The impact of selectins on mortality in stable carotid atherosclerosis. Thromb Haemost 114:632-638

Holm S, Ueland T, Dahl T, Michelsen A, Skjelland M, Russell D, Nymo S, Krohg-Sørensen K (2011) Fatty Acid binding protein 4 is associated with carotid atherosclerosis and outcome in patients with acute ischemic stroke. PLoS ONE 6:e28785

Iglseder B, Mackevics V, Stadlmayer A, Tasch G, Ladurner G, Paulweber B (2005) Plasma adiponectin levels and sonographic phenotypes of subclinical carotid artery atherosclerosis: data from the SAPHIR Study. Stroke 36:2577-2582

Ikari Y, McManus B, Kenyon J, Schwartz S (1999) Neonatal intima formation in the human coronary artery. Arterioscler Thromb Vasc Biol 19:2036-2040

Imanishi T, McBrid J, Ho Q, O'Brien K, Schwartz M, Han D (2000) Expression of cellular FLICE-inhibitory protein in human coronary arteries and in a rat vascular injury model. Am J Pathol 156:125-137

Iwamoto T, Fukuda S, Shimizu S, Takasaki M (2004) Long-term effects of lipoprotein(a) on carotid atherosclerosis in elderly Japanese. J Gerontol A Biol Sci Med Sci 59:62-67

Jaipersad A, Shantsila A, Lip G, Shantsila E (2014) Expression of monocyte subsets and angiogenic markers in relation to carotid plaque neovascularization in patients with pre-existing coronary artery disease and carotid stenosis. Ann Med 46:530-538

Jefferis B, Whincup P, Welsh P, Wannamethee G, Rumley A, Lennon L, Thomson A, Lawlor D (2010) Prospective study of matrix metalloproteinase- 9 and risk of myocardial infarction and stroke in older men and women. Atherosclerosis 208:557-563

Jia J, Wang A, Wang J, Wu J, Yan X, Zhou Y, Chen S, Zhao X (2016) Homocysteine and its relationship to asymptomatic carotid stenosis in a Chinese community population. Sci Rep 6:37361

Jiang X, Zeng H, GuoY ZZ, Tang B, Li F (2004) The expression of matrix metalloproteinases-9, transforming growth factor-beta1 and transforming growth factor-beta receptor I in human atherosclerotic plaque and their relationship with plaque stability. Chin Med J (engl) 117:1825-1829

Johnsen S, Mathiesen E, Fosse E, Joakimsen O, Stensland-Bugge E, Njølstad I, Arnesen E (2005) Elevated high-density lipoprotein cholesterol levels are protective against plaque progression: a follow-up study of 1952 persons with carotid atherosclerosis the Troms $\varnothing$ study. Circulation 112:498-504

Jurk K, Ritter M, Schriek C, Van Aken H, Droste D, Ringelstein E, Kehrel B (2010) Activated monocytes capture platelets for heterotypic association in patients with severe carotid artery stenosis. Thromb Haemost 103:1193-1202

Kadoglou N, Daskalopoulou S, Perrea D, Liapis C (2005) Matrix metalloproteinases and diabetic vascular complications. Angiology 56:173-189

Kadoglou N, Gerasimidis T, Golemati S, Kapelouzou A, Karayannacos P, Liapis C (2008) The relationship between serum levels of vascular calcifcation inhibitors and carotid plaque vulnerability. J Vasc Surg 47:55-62 
Kadoglou N, Liapis C (2004) Matrix metalloproteinases: contribution to pathogenesis, diagnosis, surveillance and treatment of abdominal aortic aneurysms. Curr Med Res Opin 20:419-432

Kassner U, Schlabs T, Rosada A, Steinhagen-Thiessen E (2015) Lipoprotein(a) dan independent causal risk factor for cardiovascular disease and current therapeutic options. Atheroscler Suppl 18:263-267

Katsuda S, Boyd H, Fligner C, Ross R, Gown A (1992) Human atherosclerosis. III. Immunocytochemical analysis of the cell composition of lesions of young adults. Am J Pathol 140:907-914

Khan T, Shah T, Prieto D, Zhang W, Price J, Fowkes G, Cooper J, Talmud P (2013) Apolipoprotein E genotype, cardiovascular biomarkers and risk of stroke: systematic review and metaanalysis of 14015 stroke cases and pooled analysis of primary biomarker data from up to 60883 individuals. Int J Epidemiol 42:475-492

Kiechl S, Schett G, Wenning G, Redlich K, Oberhollenzer M, Mayr A, Santer P, Smolen J (2004) Osteoprotegerin is a risk factor for progressive atherosclerosis and cardiovascular disease. Circulation 109:2175-2180

Kim D, Schmee J, Lee K, Thomas W (1987) Atherosclerotic lesions in the coronary arteries of hyperlipidemic swine, part 1: cell increases, divisions, losses and cells of origin in first 90 days on diet. Atherosclerosis 64:231-242

Klein J, Hegele R, Hackam D, Koschinsky M, Huff M, Spence J (2008) Lipoprotein(a) is associated differentially with carotid stenosis, occlusion, and total plaque area. Arterioscler Thromb Vasc Biol 28:1851-1856

Knoflach M, Kiechl S, Mantovani A, Cuccovillo I, Bottazzi B, Xu Q, Xiao Q, Gasperi A (2012) Pentraxin-3 as a marker of advanced atherosclerosis results from the Bruneck ARMY and ARFY Studies. PLoS ONE 7:e31474

Kofoed S, Grønholdt M, Bismuth J, Wilhjelm J, Sillesen H, Nordestgaard B (2002) Echolucent, rupture-prone carotid plaques associated with elevated triglyceride-rich lipoproteins, particularly in women. J Vasc Surg 36:783-792

Kofoed S, Wittrup H, Sillesen H, Nordestgaard B (2003) Fibrinogen predicts ischaemic stroke and advanced atherosclerosis but not echolucent, rupture-prone carotid plaques: the Copenhagen City Heart Study. Eur Heart J 24:567-576

Kolodgie F, Virmani R, Rice H, Mergner W (1990) Vascular reactivity during the progression of atherosclerotic plaque: a study in Watanabe heritable hyperlipidemic rabbits. Circ Res 66:1112-1126

Kragel A, Reddy S, Wittes J, Roberts W (1989) Morphometric analysis of the composition of atherosclerotic plaques in the four major epicardial coronary arteries in acute myocardial infarction and in sudden coronary death. Circulation 80:1747-1756

Krobot K, Hense H, Cremer P, Eberle E, Keil U (1992) Determinants of plasma fibrinogen: relation to body weight, waist-to-hip ratio, smoking, alcohol, age, and sex. results from the second MONICA Augsburg survey 1989-1990. Arterioscler Thromb 12:780-788

Kurata M, Okura T, Watanabe S, Fukuoka T, Higaki J (2006) Osteopontin and carotid atherosclerosis in patients with essential hypertension. Clin Sci (lond) 111:319-324

Ley K, Laudanna C, Cybulsky M, Nourshargh S (2007) Getting to the site of inflammation: the leukocyte adhesion cascade updated. Nat Rev Immunol 7:678-689

Li D, Liu L, Chen H, Sawamura T, Ranganathan S, Mehta J (2003) LOX-1 mediates oxidized low-density lipoprotein-induced expression of matrix metalloproteinases in human coronary artery endothelial cells. Circulation 107:612-617

Li R, Cao Z, Zhang J, Li Y, Wang R (2014) Decreased serum bilirubin is associated with silent cerebral infarction. Arterioscler Thromb Vasc Biol 34:946-951

Libby P (2012) Inflammation in atherosclerosis. Arterioscler Thromb Vasc Biol 32:2045-2051

Libby P (2003) Vascular biology of atherosclerosis: overview and state of the art. Am J Cardiol 91:3-6

Libby P, Ridker P, Hansson G, Network LT, on Atherothrombosis, (2009) Inflammation in atherosclerosis: from pathophysiology to practice. J Am Coll Cardiol 54:2129-2138

Libby P, Schoenbeck U, Mach F, Selwyn A, Ganz P (1998) Current concepts in cardiovascular pathology: the role of $\mathrm{LDL}$ cholesterol in plaque rupture and stabilization. Am J Med 104:14S-18S

Lind L, Simon T, Johansson L, Kotti S, Hansen T, Machecourt J, Ninio E, Tedqui A (2012) Circulating levels of secretory- and lipoprotein-associated phospholipase A2 activities: relation to atherosclerotic plaques and future all-cause mortality. Eur Heart J 33:2946-2954

Lusis A (2000) Atherosclerosis. Nature 407:233-241

MacPhee C, Moores K, Boyd H, Dhanak D, Ife R, Leach C, Leake D, Milliner K (1999) Lipoprotein-associated phospholipase A2, platelet-activating factor acetylhydrolase, generates two bioactive products during the oxidation of low-density lipoprotein: use of a novel inhibitor. Biochem J 338:479-487

Maitrias P, Metzinger-Le Meuth V, Nader J, Reix T, Caus T, Metzinger L (2017) The involvement of miRNA in carotid-related stroke. Arterioscler Thromb Vasc Biol 37:1608-1617

Mallat Z, Corbaz A, Scoazec A, Besnard S, Lesèche G, Chvatchko Y, Tedgui A (2001) Expression of interleukin-18 in human atherosclerotic plaques and relation to plaque instability. Circulation 104:1598-1603

Mannheim D, Herrmann J, Versari D, Gössl M, Meyer F, McConnell J, Lerman L, Lerman A (2008) Enhanced expression of Lp-PLA2 and lysophosphatidylcholine in symptomatic carotid atherosclerotic plaques. Stroke 39:1448-1455

Marsche G, Zelzer S, Meinitzer A, Kern S, Meiss I S, Pregartner G, Weghuber D, Almer G (2017) Adiponectin predicts high-density lipoprotein cholesterol efflux capacity in adults irrespective of body mass index and fat distribution. J Clin Endocrinol Metab 102:4117-4123

Martinez E, Martorell J, Riambau V (2020) Review of serum biomarkers in carotid atherosclerosis. J Vasc Surg 71:329-341

Mathiesen E, Bønaa K, Joakimsen O (2001) Low levels of highdensity lipoprotein cholesterol are associated with echolucent carotid artery plaques: the Tromsø study. Stroke 32:1960-1965

Mayer F, Binder C, Wagner O, Schillinger M, Minar E, Mlekusch W, Tsiantoulas D, Goliasch G, Hoke M (2016) Combined effects of inflammatory status and carotid atherosclerosis: A 12-Year Follow-Up Study. Stroke 47:2952-2958

McCaffrey T, Du B, Consigli S, Szabo P, Bray P, Hartner L, Weksler B, Sanborn T, Bergman G, Bush H (1997) Genomic instability in the type II TGF-beta1 receptor gene in atherosclerotic and restenotic vascular cells. J Clin Invest 100:2182-2188

McDermott M, Guralnik J, Corsi A, Albay M, Macchi C, Bandinelli S, Ferrucci $L$ (2005) Patterns of inflammation associated with peripheral arterial disease: the InCHIANTI study. Am Heart J 150:276-281

Millán H, Hernández-Mijares A, Ascaso J, Blasco M, Brea A, Díaz A, GonzálezSantos P, Mantilla T (2016) Sociedad Española de Arteriosclerosis. La auténtica dimensión del colesterol-no-HDL: colesterol aterogénico [The real measurement of non-HDL-cholesterol: Atherogenic cholesterol]. Clin Investig Arterioscler 28:265-270

Millonig G, Niederegger H, Rabl W, Hochleitner B, Hoefer D, Romani N, Wick G (2001) Network of vascular-associated dendritic cells in intima of healthy young individuals. Arterioscler Thromb Vasc Biol 21:503-508

Montecucco F (2009) Atherosclerosis is an inflammatory disease. Semin Immunopathol 31:1-3

Munro J, van der Walt J, Munro C, Chalmers J, Cox E (1987) An immunohistochemical analysis of human aortic fatty streaks. Hum Pathol 18:375-380

Nakamura T, Obata J, Takano H, Kawabata K, Sano K, Kobayashi T, Fujioka D, Saito Y (2009) High serum levels of remnant lipoproteins predict ischemic stroke in patients with metabolic syndrome and mild carotid atherosclerosis. Atherosclerosis 202:234-240

Nakashima Y, Chen Y, Kinukawa N, Sueishi K (2002) Distributions of diffuse intimal thickening in human arteries: preferential expression in atherosclerosis-prone arteries from an early age. Virchows Arch 441:279-288

Naruko T, Ueda M, Haze K, van der Wal A, van der Loos C, Itoh A, Komatsu R, Ikura Y (2002) Neutrophil infltration of culprit lesions in acute coronary syndromes. Circulation 106:2894-2900

Narula N, Dannenberg A, Olin J, Bhatt D, Johnson K, Nadkarni G, Min J, Torii S, Poojary P (2018) Pathology of peripheral artery disease in patients with critical Limb Ischemia. J Am Coll Cardiol 72:2152-2163

Natural history of aortic and coronary atherosclerotic lesions in youth. (1993) Findings from the PDAY Study. Pathobiological Determinants of Atherosclerosis in Youth (PDAY) Research Group. Arterioscler Thromb 13:1291-1298

Nishi K, Itabe H, Uno M, Kitazato K, Horiguchi H, Shinno K, Nagahiro S (2002) Oxidized LDL in carotid plaques and plasma associates with plaque instability. Arterioscler Thromb Vasc Biol 22:1649-1654 
Norata G, Marchesi P, Pirillo A, Uboldi P, Chiesa G, Maina V, Garlanda C, Mantovani A (2008) Long pentraxin 3, a key component of innate immunity, is modulated by high-density lipoproteins in endothelial cells. Arterioscler Thromb Vasc Biol 28:925-931

Norata G, Raselli S, Grigore L, Garlaschelli K, Vianello D, Bertocco S, Zambon A Catapano A (2009) Small dense LDL and VLDL predict common carotid artery IMT and elicit an inflammatory response in peripheral blood mononuclear and endothelial cells. Atherosclerosis 206:556-562

Novo S, Avellone G, Di Garbo V, Abrignani M, Liquori M, Panno A, Strano A (1992) Prevalence of risk factors in patients with peripheral arterial disease. A clinical and epidemiological evaluation. Int Angiol 11:218-229

Novo S, Failla G, Liquori M, Longo B, Gennaro C, Corda M, Barbagallo M, Abrignani M, Barbagallo Sangiorgi G, Strano A (1991) Vascular damage in arterial hypertension: its noninvasive assessment. Cardiologia 36:323-337

Olson F, Thurison T, Ryndel M, Høyer-Hansen G, Fagerberg B (2010) Soluble urokinase-type plasminogen activator receptor forms in plasma as markers of atherosclerotic plaque vulnerability. Clin Biochem 43:124-130

Orekhov A, Andreeva E, Mikhailova I, Gordon D (1998) Cell proliferation in normal and atherosclerotic human aorta: proliferative splash in lipid-rich lesions. Atherosclerosis 139:41-48

Paffen E, Vos H, Bertina R (2004) C-reactive protein does not directly induce tissue factor in human monocytes. Arterioscler Thromb Vasc Biol 24:975-981

Parra E, Panzoldo N, De Zago V, Scherrer D, Alexandre F, Bakkarat J, Nunes V, Nakandakare E (2014) HDL size is more accurate than HDL cholesterol to predict carotid subclinical atherosclerosis in individuals classified as low cardiovascular risk. PLoS ONE 9:e114212

Paternoster L, Martínez González N, Lewis S, Sudlow C (2008) Association between apolipoprotein $\mathrm{E}$ genotype and carotid intima-media thickness may suggest a specific effect on large artery atherothrombotic stroke. Stroke 39:48-54

Pedrigi R, de Silva R, Bovens S, MehtaV PE, Krams R (2014) Thin-cap fibroatheroma rupture is associated with a fine interplay of sand wall stress. Arterioscler Thromb Vasc Biol 34:2224-2231

Pelisek J, Rudelius M, Zepper P, Poppert H, Reeps C, Schuster T, Eckstein H (2009) Multiple biological predictors for vulnerable carotid lesions. Cerebrovasc Dis 28:601-610

Persson J, Strawbridge R, McLeod O, Gertow K, Silveira A, Baldassarre D, Van Zuydam N, Shah S (2015) Sex-specific effects of adiponectin on carotid intima-media thickness and incident cardiovascular disease. J Am Heart Assoc 4:e001853

Peters S, Lind L, Palmer M, Grobbee D, Crouse J, O'Leary D, Evans G, Raichlen J (2012) METEOR study group. Increased age, high body mass index and low HDL-C levels are related to an echolucent carotid intima-media: the METEOR study. J Intern Med 272:257-266

Piepoli M, Hoes A, Agewall S, Albus C, Brotons C, Catapano A, Cooney M, Corrà U, Cosyns B, Deaton C (2016) 2016 European Guidelines on cardiovascular disease prevention in clinical practice: The Sixth Joint Task Force of the European Society of Cardiology and Other Societies on Cardiovascular Disease Prevention in Clinical Practice (constituted by representatives of 10 societies and by invited experts)Developed with the special contribution of the European Association for Cardiovascular Prevention \& Rehabilitation (EACPR). Eur Heart J 37:2315-2381

Pini R, Faggioli G, Fittipaldi S, Pasquinelli G, Tonon C, Beltrandi E, Mauro R, Stella A (2013) Inflammatory mediators and cerebral embolism in carotid stenting: new markers of risk. J Endovasc Ther 20:684-694

Podrez E, Schmitt D, Hoff H, Hazen S (1999) Myeloperoxidase-generated reactive nitrogen species convert LDL into an atherogenic form in vitro. J Clin Invest 103:1547-1560

Pokrovsky S, Afanasieva O, Safarova M, Balakhonova T, Matchin Y, Adamova I, Konovalov G, Ezhov M (2017) Specific Lp(a) apheresis: A tool to prove lipoprotein(a) atherogenicity. Atheroscler Suppl 30:166-173

Puz P, Lasek-Bal A, Ziaja D, Kazibutowska Z, Ziaja K (2013) Inflammatory markers in patients with internal carotid artery stenosis. Arch Med Sci 2:254-260

Ridker P, Howard C, Walter V, Everett B, Libby P, Hensen J, Thuren T, CANTOS Pilot Investigative Group (2012) Effects of interleukin-1b inhibition with canakinumab on hemoglobin A1c, lipids, C-reactive protein, interleukin-6, and fibrinogen: a phase llb randomized, placebo-controlled trial. Circulation 126:2739-2748

Ridker P, MacFadyen J, Everett B, Libby P, Thuren T, Glynn R, CANTOS Trial Group (2018) Relationship of C-reactive protein reduction to cardiovascular event reduction following treatment with canakinumab: a secondary analysis from the CANTOS randomised controlled trial. Lancet 391:319-328

Rigamonti F, Carbone F, Montecucco F, Bonaventura A, Liberale L, Burger F, Roth A, Bertolotto M (2018) Serum lipoprotein (a) predicts acute coronary syndromes in patients with severe carotid stenosis. Eur J Clin Invest 48:e12888

Rosenfeld M, Tsukada T, Chait A, Bierman E, Gown A, Ross R (1987) Fatty streak expansion and maturation in Watanabe Heritable Hyperlipemic and comparably hypercholesterolemic fat-fed rabbits. Arteriosclerosis 7:24-34

Rozalski R, Migdalski A, Gackowski D, Guz J, Siomek A, Foksinski M, Szpila A, Zarakowska E (2013) Does morphology of carotid plaque depend on patient's oxidative stress? Clin Biochem 46:1030-1035

Rudd J, Myers K, Bansilal S, Machac J, Woodward M, Fuster V, Farkouh M, Fayad Z (2009) Relationships among regional arterial inflammation, calcification, risk factors, and biomarkers: a prospective fluorodeoxyglucose positron-emission tomography/computed tomography imaging study. Circ Cardiovasc Imaging 2:107-115

Sakakura K, Nakano M, Otsuka F, Ladich E, Kolodgie F, Virmani R (2013) Pathophysiology of atherosclerosis plaque progression. Heart Lung Circ 22:399-411

Samman Tahhan A, Hayek S, Sandesara P, Hajjari J, Hammadah M, O'Neal W, Kelli H, Alkhoder A (2017) Circulating soluble urokinase plasminogen activator receptor levels and peripheral arterial disease outcomes. Atherosclerosis 264:108-114

Santos V, Caffaro R, Pozzan G, Saieg M, Castelli V (2008) Comparative histological study of atherosclerotic lesions and microvascular changes in amputated lower limbs of diabetic and non-diabetic patients. Arq Bras Endocrinol Metabol 52:1115-1123

Sarlon-Bartoli G, Boudes A, Buffat C, Bartoli M, PiercecchiMarti M, Sarlon E, Arnaud L, Bennis Y (2012) Circulating lipoprotein-associated phospholipase $\mathrm{A} 2$ in high-grade carotid stenosis: a new biomarker for predicting unstable plaque. Eur J Vasc Endovasc Surg 43:154-159

Sayed S, Cockerill G, Torsney E, Poston R, Thompson M, Loftus I (2009) Elevated tissue expression of thrombomodulatory factors correlates with acute symptomatic carotid plaque phenotype. Eur J Vasc Endovasc Surg 38:20-25

Schillinger M, Exner M, Mlekusch W, Sabeti S, Amighi J, Nikowitsch R, Timmel E, Kickinger, (2005) Inflammation and Carotid Artery-Risk for Atherosclerosis Study (ICARAS). Circulation 111:2203-2209

Schiro A, Wilkinson F, Weston R, Smyth J, Serracinolnglott F, Alexander M (2015) Elevated levels of endothelialderived microparticles, and serum CXCL9 and SCGF- $\beta$ are associated with unstable asymptomatic carotid plaques. Sci Rep 5:16658

Schneiderman J, Schaefer K, Kolodgie F, Savion N, Kotev-Emeth S, Dardik R, Simon A, Halak M (2012) Leptin locally synthesized in carotid atherosclerotic plaques could be associated with lesion instability and cerebral emboli. J Am Heart Assoc 1:e001727

Schulze Horn C, Ilg R, Sander K, Bickel H, Briesenick C, Hemmer B, Poppert H, Sander D (2009) High-sensitivity C-reactive protein at different stages of atherosclerosis: results of the INVADE study. J Neurol 256:783-791

Schwartz S, deBlois D, O'Brien E (1995) The intima. Soil for atherosclerosis and restenosis. Circ Res 77:445-465

Shindo A, Tanemura H, Yata K, Hamada K, Shibata M, Umeda Y, Asakura F, Toma N (2014) Inflammatory biomarkers in atherosclerosis: pentraxin 3 can become a novel marker of plaque vulnerability. PLOS ONE 9:e100045

Singh R, Mengi S, Xu Y, Arneja A, Dhalla N (2002) Pathogenesis of atherosclerosis: a multifactorial process. Exp Clin Cardiol 7:40-53

Sofat R, Cooper J, Kumari M, Casas J, Mitchell J, Acharya J, Thom S, Hughes A (2016) Circulating apolipoprotein E concentration and cardiovascular disease risk: meta-analysis of results from three studies. PLoS Med 13:e1002146

Stary H (2000) Natural history and histological classification of Atherosclerotic lesions: an update. Arterioscler Thromb Vasc Biol 20:1177-1178

Stary H (1989) Evolution and progression of atherosclerotic lesions in coronary arteries of children and young adults. Arteriosclerosis 9: |-19-|-32 
Stary H (1987) Macrophages, macrophage foam cells, and eccentric intimal thickening in the coronary arteries of young children. Atherosclersis 64:91-108

Stary H, Chandler A, Dinsmore R, Fuster V, Glagov S, Insull W, Rosenfeld M, Schwartz C, Wagner W, Wissler R (1995) A definition of advanced types of atherosclerotic lesions and a histological classification of atherosclerosis. A report from the Committee on Vascular Lesions of the Council on Arteriosclerosis, American Heart Association. Circulation 92:1355-1374

Stary H, Chandler A, Glagov S, Guyton J, Insull W, Rosenfeld M, Schaffer S, Schwartz C, Wagner W, Wissler R (1994) A definition of initial, fatty streak, and intermediate lesions of atherosclerosis. A report from the Committee on Vascular Lesions of the Council on Arteriosclerosis, American Heart Association. Circulation 89:2462-2478

Stec J, Silbershatz H, Tofler G, Matheney T, Sutherland P, Lipinska I, Massaro J, Wilson P, Muller J (2000) Association of fibrinogen with cardiovascular risk factors and cardiovascular disease in the Framingham Offspring Population. Circulation 102:1634-1638

Sternberg Z, Ghanim H, Gillotti K, Tari J, Munschauer F, Curl R, Noor S, Yu $J$ (2013) Flow cytometry and gene expression profiling of immune cells of the carotid plaque and peripheral blood. Atherosclerosis 229:338-347

St-Pierre A, Cantin B, Dagenais G, Mauriège P, Bernard P, Després J, Lamarche B (2005) Low-density lipoprotein subfractions and the long-term risk of ischemic heart disease in men: 13-year followup data from the Québec Cardiovascular Study. Arterioscler Thromb Vasc Biol 25:553-559

Straface G, Biscetti F, Pitocco D, Bertoletti G, Misuraca M, Vincenzoni C, Snider F, Arena V (2011) Assessment of the genetic effects of polymorphisms in the osteoprotegerin gene, TNFRSF11B, on serum osteoprotegerin levels and carotid plaque vulnerability. Stroke 42:3022-3028

Strong J, Malcom G, McMahan C, Tracy R, Newman W, Herderick E, Cornhill $J$ (1999) Prevalence and extent of atherosclerosis in adolescents and young adults: implications for prevention from the Pathobiological Determinants of Atherosclerosis in Youth Study. JAMA 281:727-735

Szmitko P, Wang C, Weisel R, De Almeida J, Anderson T, Verma S (2003a) New markers of inflammation and endothelial cell activation: Part I. Circulation 108:1917-1923

Szmitko P, Wang C, Weisel R, Jeffries G, Anderson T, Verma S (2003b) Biomarkers of vascular disease linking inflammation to endothelial activation: Part II. Circulation 108:2041-2048

Tabas I (2000) Cholesterol and phospholipid metabolism in macrophages. Biochim Biophys Acta 1529:164-174

Tabas I, Li Y, Brocia R, Xu S, Swenson T, Williams K (1993) Lipoprotein lipase and sphingomyelinase synergistically enhance the association of atherogenic lipoproteins with smooth muscle cells and extracellular matrix: a possible mechanism for low density lipoprotein and lipoprotein(a) retention and macrophage foam cell formation. J Biol Chem 268:20419-21432

Tabas I, Marathe S, Keesler G, Beatini N, Shiratori Y (1996) Evidence that the initial up-regulation of phosphatidylcholine biosynthesis in free cholesterol-loaded macrophages is an adaptive response that prevents cholesterol-induced cellular necrosis. Proposed role of an eventual failure of this response in foam cell necrosis in advanced atherosclerosis. J Biol Chem 271:22773-22781

Tanaskovic S, Radak D, Aleksic N, Calija B, MaravicStojkovic V, Nenezic D, Ilijevski N, Popov P (2018) Scoring system to predict early carotid restenosis after eversion endarterectomy by analysis of inflammatory markers. J Vasc Surg 68:118-127

Taubman M, Fallon J, Schecter A, Giesen P, Mendlowitz M, Fyfe B, Marmur J (1997) Tissue factor in the pathogenesis of atherosclerosis. Thromb Haemost 78:200-204

Taylor K, Glagov S, Zarins C (1989) Preservation and structural adaptation of endothelium over experimental foam cell lesions: quantitative ultrastructural study. Arteriosclerosis 9:881-894

Thompson S, Keinast J, Pyke S, Haverkate F, van de Loo J (1995) For the European Concerted Action on Thrombosis and Disabilities Angina Pectoris Study Group. Hemostatic factors and the risk of myocardial infarction or sudden death in patients with angina pectoris. N Engl J Med 332:635-641
Tiozzo E, Gardener H, Hudson B, Dong C, Della-Morte D, Crisby M, Goldberg R, Elkind M (2014) High-density lipoprotein subfractions and carotid plaque: the Northern Manhattan Study. Atherosclerosis 237:163-168

Touboul P, Labreuche J, Bruckert E, Schargrodsky H, Prati P, Tosetto A, Hernandez-Hernandez R, Woo K (2014) HDL-C, triglycerides and carotid IMT: a meta-analysis of 21,000 patients with automated edge detection IMT measurement. Atherosclerosis 232:65-71

Triantafllos G, Giannakopoulos T, Avgerinos E, Moulakakis K, Kadoglou N, Preza O, Papapetrou A, Papasideris C, Liapis C (2011) Biomarkers for diagnosis of the vulnerable atherosclerotic plaque. Interv Cardiol 3:223-233

Tzoulaki I, Murray G, Price J, Smith F, Lee A, Rumley A, Lowe G (2006) Hemostatic factors, inflammatory markers, and progressive peripheral atherosclerosis: the Edinburgh Artery Study. Am J Epidemiol 163:334-341

van den Berg M, van der Graaf Y, de Borst G, Kappelle L, Nathoe H, Visseren F, SMART Study Group (2016) Low-density lipoprotein cholesterol, nonhigh-density lipoprotein cholesterol, triglycerides, and apolipoprotein $\mathrm{B}$ and cardiovascular risk in patients with manifest arterial disease. Am J Cardiol 118:804-810

van der Wal A, Becker A, van der Loos C, Das P (1994) Site of intimal rupture or erosion of thrombosed coronary atherosclerotic plaques is characterized by an inflammatory process irrespective of the dominant plaque morphology. Circulation 89:36-44

Vaya J (2013) The association between biomarkers in the blood and carotid plaque composition-focusing on oxidized lipids, oxysterols and plaque status. Biochem Pharmacol 86:15-18

Velican D, Velican C (1980) Atherosclerotic involvement of the coronary arteries of adolescents and young adults. Atherosclerosis 36:449-460

Venugopal S, Devaraj S, Yuhanna I, Shaul P, Jialal I (2002) Demonstration that C-reactive protein decreases eNOS expression and bioactivity in human aortic endothelial cells. Circulation 106:1439-1441

Verma S, Kuliszewski M, Li S, Szmitko P, Zucco L, Wang C, Badiwala M, Mickle D (2004) C-reactive protein attenuates endothelial progenitor cell survival, differentiation, and function: further evidence of a mechanistic link between C-reactive protein and cardiovascular disease. Circulation 109:2058-2067

Verma S, Li S, Badiwala M, Weisel R, Fedak P, Li R, Dhillon B, Mickle D (2002) Endothelin antagonism and interleukin- 6 inhibition attenuate the proatherogenic effects of C-reactive protein. Circulation 105:1890-1896

Vik A, Mathiesen E, Notø A, Sveinbjørnsson B, Brox J, Hansen J (2007) Serum osteoprotegerin is inversely associated with carotid plaque echogenicity in humans. Atherosclerosis 191:128-134

Virmani R, Kolodgie F, Burke A, Farb A, Schwartz S (2000) Lessons from sudden coronary death: a comprehensive morphological classifcation scheme for atherosclerotic lesions. Arterioscler Thromb Vasc Biol 20:1262-1275

Volanakis J (2001) Human C-reactive protein: expression, structure, and function. Mol Immunol 38:189-197

Walsh K, Hart K, Roll S, Sperling M, Unruh D, Davidson W, Lindsell C, Adeoye O (2016) Apolipoprotein A-I and paraoxonase-1 are potential blood biomarkers for ischemic stroke diagnosis. J Stroke Cerebrovasc Dis 25:1360-1365

Wang A, Huang X, Liu X, Su Z, Wu J, Chen S, Liu X, Ruan C (2017) No association between high-sensitivity $C$-reactive protein and carotid intima-media progression: the APAC Study. J Stroke Cerebrovasc Dis 26:252-259

Wang C, Li S, Weisel R, Fedak P, Dumont A, Szmitko P, Li R (2003) C-reactive protein upregulates angiotensin type 1 receptors in vascular smooth muscle. Circulation 107:1783-1790

Wekesa A, Cross K, O'Donovan O, Dowdall J, O'Brien O, Doyle M, Byrne L, Phelan J (2014) Predicting carotid artery disease and plaque instability from cell-derived microparticles. Eur J Vasc Endovasc Surg 48:489-495

Wentzel J, Chatzizisis Y, Gijsen F, Giannoglou G, Feldman C, Stone P (2012) Endothelial shear stress in the evolution of coronary atherosclerotic plaque and vascular remodelling: current understanding and remaining questions. Cardiovasc Res 96:234-243

WHO Study Group on the Classification of Atherosclerotic Lesions, World Health Organization (1958) Classification of atherosclerotic lesions: report of a study group. World Health Organ Tech Rep Ser 57:1-20

Willeit P, Thompson S, Agewall S, Bergström G, Bickel H, Catapano A, Chien K, de Groot E (2016) Inflammatory markers and extent and progression of early atherosclerosis: meta-analysis of individual-participant-data from 20 prospective studies of the PROG-IMT collaboration. Eur J Prev Cardiol 23:194-205 
Wissler R, Vesselinovitch D (1968) Comparative pathogenetic patterns in atherosclerosis. Adv Lipid Res 6:181-206

Xu D, Chan W, Leung B, Hunter D, Schulz K, Carter R, Mclnnes I, Robinson J, Liew F (1998) Selective expression and functions of interleukin 18 receptor on Thelper (Th) type 1 but not Th2 cells. J Exp Med 188:1485-1492

Yamagami H, Kitagawa K, Nagai Y, Hougaku H, Sakaguchi M, Kuwabara K, Kondo K, Masuyama T (2004) Higher levels of interleukin-6 are associated with lower echogenicity of carotid artery plaques. Stroke 35:677-681

Yang M, Yu Y, Walsh W, Yang J, Baker L, Lennox A, Crowe P, Varcoe R (2016) A microscopic and biomarker evaluation of embolic filter debris collected during carotid artery stenting. J Endovasc Ther 23:275-284

Yasojima K, Schwab C, McGeer E, McGeer P (2001) Generation of C-reactive protein and complement components in atherosclerotic plaques. Am J Pathol 158:1039-1051

Yin R, Ma A, Pan X, Yang S (2017) Biomarkers of cerebral microembolic signals. Clin Chim Acta 475:164-168

Young J, Libby P, Schönbeck U (2002) Cytokines in the pathogenesis of atherosclerosis. Thromb Haemost 88:554-567

Yu F, Lu J, Li Z, Zhou X, Zeng S, Zhan Q, Yuan M, Yang Q (2017) Correlation of plasma vascular endothelial growth factor and endostatin levels with symptomatic intra- and extracranial atherosclerotic stenosis in a Chinese Han population. J Stroke Cerebrovasc Dis 26:1061-1070

Zaninotto M, Mion M, Novello E, Altinier S, Plebani M (2007) New biochemical markers: from bench to bedside. Clin Chim Acta 381:14-20

Zheng J, Wu Y, Li Z, Wang H, Xiao W, Shi Y, Wang T (2016) Low serum total bilirubin concentration was associated with increased high sensitive $C$ reactive protein level in patients with impaired glucose tolerance and type 2 diabetes mellitus subjects. Clin Lab 62:901-907

Zhou Y, Han W, Gong D, Man C, Fan Y (2016) Hs-CRP in stroke: a meta-analysis. Clin Chim Acta 453:21-27

\section{Publisher's Note}

Springer Nature remains neutral with regard to jurisdictional claims in pub-

lished maps and institutional affiliations.

\section{Submit your manuscript to a SpringerOpen ${ }^{\circ}$ journal and benefit from:}

- Convenient online submission

- Rigorous peer review

- Open access: articles freely available online

- High visibility within the field

- Retaining the copyright to your article

Submit your next manuscript at $>$ springeropen.com 